OPEN ACCESS

Edited by:

Heng Ma

Fourth Military Medical University,

China

Reviewed by:

Yingyun Gong,

Nanjing Medical University, China

Semir Özdemir.

Akdeniz University, Turkey

*Correspondence:

Jun Li

Jun Li@ibms.pumc.edu.cn

Specialty section:

This article was submitted to

Integrative Physiology,

a section of the journal

Frontiers in Physiology

Received: 29 April 2021

Accepted: 23 June 2021

Published: 21 July 2021

Citation:

Tan Q, Liang N, Zhang X and Li J (2021) Dynamic Aging: Channeled

Through Microenvironment.

Front. Physiol. 12:702276.

doi: 10.3389/fphys.2021.702276

\section{Dynamic Aging: Channeled Through Microenvironment}

\author{
Qing Tan, Na Liang, Xiaoqian Zhang and Jun Li*
}

State Key Laboratory of Medical Molecular Biology, Department of Biochemistry and Molecular Biology, Institute of Basic Medical Sciences, Chinese Academy of Medical Sciences and Peking Union Medical College, Beijing, China

Aging process is a complicated process that involves deteriorated performance at multiple levels from cellular dysfunction to organ degeneration. For many years research has been focused on how aging changes things within cell. However, new findings suggest that microenvironments, circulating factors or inter-tissue communications could also play important roles in the dynamic progression of aging. These out-ofcell mechanisms pass on the signals from the damaged aging cells to other healthy cells or tissues to promote systematic aging phenotypes. This review discusses the mechanisms of how senescence and their secretome, $\mathrm{NAD}^{+}$metabolism or circulating factors change microenvironments to regulate systematic aging, as well as the potential therapeutic strategies based on these findings for anti-aging interventions.

Keywords: aging, SASP, microenvironment, $\mathrm{NAD}^{+}$, intercellular communication

\section{INTRODUCTION}

With $100 \%$ incidence rate and individualized symptoms, aging is a highly complex process which simultaneously affects multiple organ systems (Ahadi et al., 2020). In addition to probing for the cell-autonomous mechanisms of aging, there is growing awareness of that deregulated intercellular communication contributes to decline in tissue/organ health with aging (Lopez-Otin et al., 2013). Intercellular communication refers to both direct interactions between neighboring cells and indirect cell communication via various message signals. A harmonious intercellular communication system is very important for organ development, stress response, cell survival and etc. In contrast, a disordered intercellular communication can be detrimental in aging progression and promote aging-related diseases (Fafian-Labora and O'Loghlen, 2020).

The best-known means of regulating intercellular communication are soluble factors in blood or extracellular matrix that can easily cross cell membrane to take effect through autocrine or paracrine signaling (Acosta et al., 2013). These soluble factors exist in various forms including proteins, metabolites or nucleic acids. Protein factors are the most well-studied, with the proactive secretome of senescent cells, known as senescence-associated secretory phenotype (SASP) factors, accounting for the vast majority. Senescent cells amass with age and secret more and more SASP factors into extracellular matrix, resulting in chronic low-grade immune response activation, or "Inflammaging," which systematically compromise physiological functions and contribute to agerelated dysfunctions in different organs or tissues such as neurodegeneration (Frederiksen et al., 2019; Ogrodnik et al., 2021), atherosclerosis (Childs et al., 2016), osteoarthritis cancer (Jeon et al., 2018), and kidney dysfunction (Valentijn et al., 2018), etc. Apart from SASP factors, non-SASP 
circulating protein factors and metabolites, particularly $\mathrm{NAD}^{+}$, have been extensively researched in recent years for their roles in aging development. Studies designed to counteract the change of these factors or metabolites caused by aging have shown that they are promising targets for anti-aging interventions. Moreover, recent studies have accumulated evidence that noncoding RNA molecules are linked to several biological aspects of aging such as senescence or autophagy, indicating more research attention needed.

Here, we review some major means of intercellular communication that affect aging such as senescence and senescence associated secretion phenotype (SASP) in the context of physiological or pathological scenario. We also go over the regulatory mechanisms of circulating aging-related factors including proteins factors, $\mathrm{NAD}^{+}$and non-coding RNAs, as well as potential anti-aging strategies that target them. In light of the close tie of $\mathrm{NAD}^{+}$metabolism with aging, we discuss how different organs use this highly mobile cofactor to shape cellular microenvironment. In light of the close tie of $\mathrm{NAD}^{+}$ metabolism with aging, we-discuss how different organs use this highly mobile cofactor to shape cellular microenvironment.

\section{PART 1: CELLULAR SENESCENCE AND SASP MODULATE THE DEVELOPMENT OF AGING MICROENVIRONMENT}

Hayflick and Moorhead (1961) observed that the primary cells would have replicative exhaustion after about 50 generations in vitro. It was the first evident that replicative senescence was the driver of organismal aging. Cellular senescence is a relatively stable physiological state in which cells lose their ability to proliferate and resistant to apoptosis. It is characterized by permanent cell cycle arrest, enlarged cell size, persistent DNA damage response, abnormal protein degradation, impaired nutrient response, and increased inflammation level (Lopez-Otin et al., 2013). Senescent cells have been proven to accumulate in the aged mice tissues, and clearance of senescent cells can ameliorate these aging phenotypes (Baker et al., 2011, 2016). Hereby, these causative connections qualify cellular senescence as a hallmark of aging and attract enormous research interest (Lopez-Otin et al., 2013). Although senescent cells are almost found in almost all kinds of tissues of aged animals, it is believed that senescence originates from single damaged cells and could propagate to neighboring or remote tissues via its SASP secretome (Coppe et al., 2010; Childs et al., 2015). A strategy aiming to remove senescent cells named Senolysis has shown great potential in retarding aging phenotypes in multiple aging-related diseases including osteoarthritis, atherosclerosis (Childs et al., 2016), chemotoxicity (Baar et al., 2017), chronic obstructive pulmonary disease (COPD) (Chilosi et al., 2013), and idiopathic pulmonary fibrosis (IPF) (Cai et al., 2020). It is not exaggerated that senescence and SASP are the major players when it comes to the cellular communication between tissues and microenvironmental homeostasis during aging. In this part, by summarizing the features of senescence, we discuss about the cell types mostly vulnerable to senescence in different tissues and how senescent cells jeopardize functions of other tissues via SASP secretion.

\section{The Features of Senescence and SASP}

A number of features of senescence have been characterized, which could be used as proper biomarkers or potential therapeutic targets. Senescent cells generally display dramatically morphological changes, increased $\beta$-galactosidase activity, stable cell cycle arrest, persistent DNA damage response, metabolic reprogramming and significant chromatin remodeling (Figure 1). Senescence can be identified by certain molecular biomarkers such as induction of cell cycle inhibitors p21 or p16 ${ }^{\text {Ink } 4 \mathrm{a}}$, upregulated DNA damage markers $\gamma \mathrm{H} 2 \mathrm{AX}$ or ATM, nuclear depletion of HGMB1 and reduced Lamin B1 level (Freund et al., 2012; Tchkonia et al., 2013; Wiley et al., 2016; Kumar et al., 2020). Senescent cells can release of a special panel of SASP secretome. The secretion of SASP factors change microenvironment and affect even remote tissue via paracrine, which is believed to contribute to organ degeneration with aging (Campisi, 2013).

The phenotypic manifestations of SASP are heterogeneous and induced by different internal and external stimulus including telomere attrition, DNA damage, oncogenic activation, mitochondrial dysfunction or epigenetic alterations (Lopez-Otin et al., 2013; Tchkonia et al., 2013). The SASP factors are mainly made of different types of soluble components including pro-inflammatory cytokines, growth factors, chemokines and extracellular matrix-degrading proteins (Gorgoulis et al., 2019). This particular combination of signaling factors and the proteases that degrade extracellular matrix (ECM) to facilitate signal transduction has made SASP a powerful mechanism to modulate intercellular communication. The secretion of SASP factors is considered as a major detrimental aspect of senescence because it promotes chronic inflammation, induces fibrosis and causes stem cell exhaustion (Freund et al., 2010; He and Sharpless, 2017; Schafer et al., 2017). However, it has also been shown to favor embryonic development or wound healing, suggesting whether beneficial or detrimental effects the SASP exerts depends on the physiological and pathological context (Wilkinson and Hardman, 2020). For example, a recent study has shown that transiently exposing the primary mouse keratinocytes to SASP factors increased cell stemness and regenerative capacity in vivo, while prolonged exposure caused secondary senescence and hindered regeneration (Ritschka et al., 2017). This suggests senescence has more complicated physiological roles than currently understood.

The relationship between SASP and microenvironmental homeostasis is complex and paradoxical (Figure 1). In some cases, SASP factors can help to maintain tissue homeostasis by positively regulating tissue regeneration and repair (Nehme et al., 2020). For instance, transient secretion of platelet-derived growth factor AA (PDGF-AA), a SASP factor categorized as growth factor, attracts leukocytes to the wounded sites and contributes to wound resolution (Demaria et al., 2014). In other cases, SASP factors like IL-6, IL-8, MCPs and MIPs can act on neighboring cells to disrupt tissue homeostasis, cause chronic inflammation and accelerate disease exacerbation in the body (Terlecki-Zaniewicz et al., 2018). Therefore, the effects of SASP 


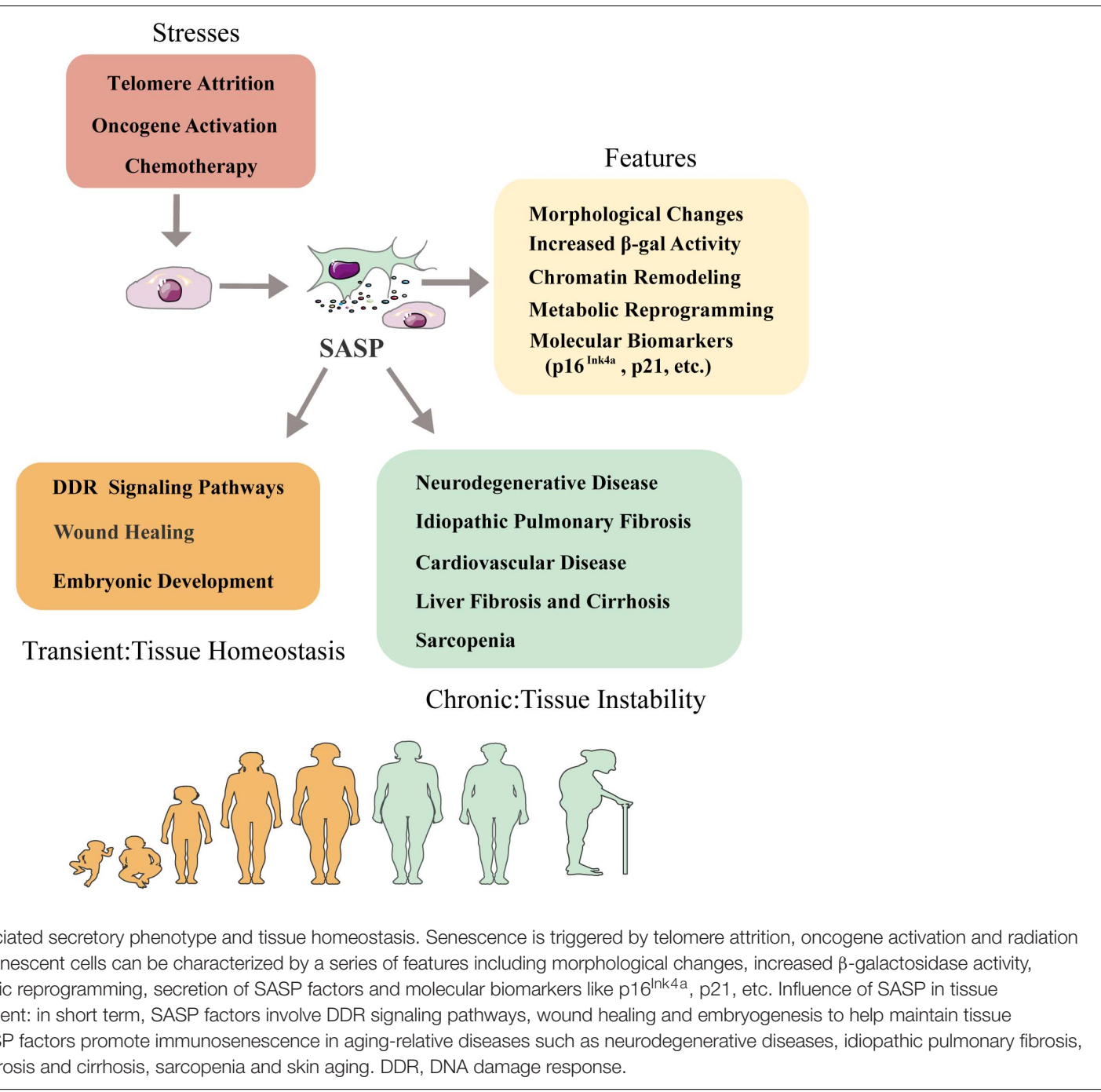

on microenvironment could be highly individualized given the fact that different tissue or organ has different cell compositions and mitotic status. Next, we discuss the effects of SASP factors on different tissues in the following subtopics (Figure 2).

\section{The Effects of SASP Factors on Immune Functions}

The effects of aging on immune system can be summarized as two terms: "inflammaging" and "immunosenescence." "Inflammaging" refers to the chronic low-level pro-inflammatory development within tissues during aging (Franceschi et al., 2018). Immunosenescence demonstrates as a gradual reduction in immune cells, inmate and adaptive immune functions with aging (Aw et al., 2007b). Despite their conceptional difference, inflammaging and immunosenescence join forces with SASP to drive age-related immune function decline, forming a vicious cycle. Inflammaging increases the production of inflammatory factors, most of which are SASP factors, aggravates the reduction in immune response and eventually leads to immunosenescence. The decreased immune response impedes immune cells clearance of damaged cells, increasing the risk of generating more senescent cells and SASP factors, which lead to a higher level of inflammaging. Therefore, Senescence and SASP factors have the most comprehensive effects on immune system which might indirectly drive the function decline of other systems.

\section{Immunosenescence Compromises Immune Responses}

In the age-associated diseases such as neurodegeneration, cardiovascular diseases or cancer, SASP factors are considered to be the major reason for immunosenescence mechanism to cause persistent prolonged inflammation and progenitor cell exhaustion (Franceschi and Campisi, 2014; Jian et al., 2020). Immunosenescence decreases the response to vaccinations, impairs wound healing and enhance the susceptibility to virus infection, malignancy, or autoimmunity (Aw et al., 2007a; Sanada et al., 2018). SASP factors are temporally regulated, the first wave of SASP factors such as transforming growth factor- $\beta 1$ (TGF$\beta 1)$ and TGF- $\beta 3$ are typically immunosuppressive, whereby the second wave of the SASP often consists of proinflammatory factors (Ito et al., 2017). One of the most important functions of immune system is immunosurveillance on tumorigenesis. SASP 


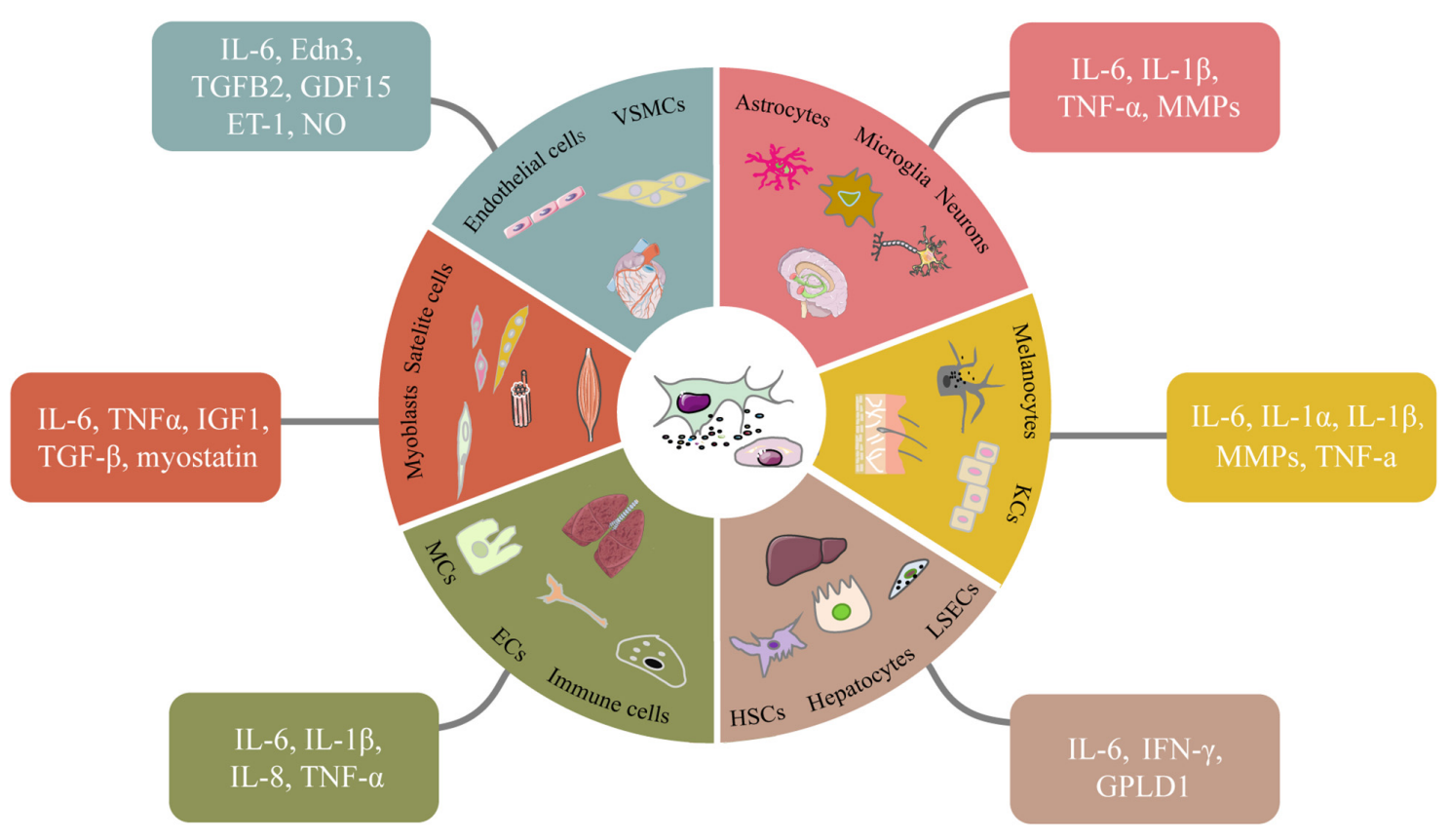

FIGURE 2 | Senescent cell types and the SASP factors they secret in different tissues. In different tissues, various senescent cells secrete classic or specific SASP factors in autocrine and paracrine ways. Some signaling molecules such as NO which accordingly change to elevate chronic inflammation, induce tissue dysfunction and accelerate aging. VSMCs, vascular smooth muscle cells. LSECs, liver sinusoidal endothelial cells; HSCs, hepatic stellate cells.

secretion may change immune system into pro-tumorigenesis environment by releasing pro-inflammatory factors in autocrine and paracrine ways. Senescent fibroblasts secrete a large number of CXC-chemokine ligand 1 (CXCL1), CXCL2, IL-6, insulinlike growth factor binding proteins (IGFBPs) and colony stimulating factors (CSFs) to accelerate the development of tumors (Nacarelli et al., 2019). The IL-1 pathway significantly promoted pancreatic tumor progression and immune cell infiltration by controlling the secretion of IL- $1 \alpha$ and other SASP factors (Lau et al., 2019). Together, these factors enhance the severity of cancer and accelerate age-related cell damage, thus further promote a metabolic microenvironment suitable for cancer development. However, in some cases senescence could be used against tumorigenesis. A combination of IFN- $\gamma$ and tumor necrosis factor (TNF) directly drove tumor cells into senescence (Braumuller et al., 2013). Another exciting study used chimeric antigen receptor (CAR) $\mathrm{T}$ cells that target an antigen (uPAR) specific to senescent human cells to reverse aging-associated pathologies and improve outcome of cancer treatment (Amor et al., 2020). Hereby, senescence has made immune system out to be a double-blade sword on cancer, which might have potential in designing cancer-treating drugs.

\section{Inflammaging Promotes Inflammatory Microenvironment}

Various causes contribute to inflammaging which include SASP (Lopez-Otin et al., 2013). Acute inflammation, essential for keeping body healthy, occurs immediately after stimulated by environmental or internal stressors such as alcohol, trauma, or pathogens (Han et al., 2015). Opposite to acute inflammation, there is another form of inflammation characterized as chronic, sterile, low-grade inflammation aggravating with aging process, named "Inflammaging" (Franceschi et al., 2018). As an important driving force of aging and age-associated diseases, Inflammaging is associated with dysregulated immune system and increased secretion of pro-inflammatory factors such as IL-1, IL-6, IL-8, IL13, IL-18, TNF, etc. (Franceschi et al., 2018; Fulop et al., 2019). IL-6, a major cytokine contributing inflammaging, is considered to be a useful biomarker in the elderly people to predict 3year to 6-year mortality (Alley et al., 2007). Gradually increased inflammatory states in elderly people result in decreased physical functions and increased susceptibility to chronic diseases (Vasto et al., 2009). However, the centenarian and their offspring often have relatively lower inflammation index (Arai et al., 2015). Inducing chronic inflammation by knocking out $n f k b 1$, a subunit of NF- $\mathrm{B}$, accelerated aging phenotypes in multiple organs (Jurk et al., 2014). Besides age, there are other risk factors of inflammaging such as visceral obesity (Frasca et al., 2017), genetic variants (Smith and Humphries, 2009), gut dysbios (Rampelli et al., 2013), accumulation of senescent cells (van Deursen, 2014), and mental stress (Miller and Raison, 2016). The pro-inflammatory SASP cytokines secreted by senescent cells are the major carriers responsible for the spread and aggravation of inflammaging which turns microenvironment into hostile conditions.

Inflammaging also contributes to the development of many age-associated chronic diseases such as cardiovascular disorders, neurodegenerations, cancers and metabolic diseases (Ferrucci and Fabbri, 2018; Armutcu, 2019). The oxidized low-density lipoprotein on artery walls caused initiation and 
development of atherosclerosis by inducing inflammation, while the atherosclerotic plaques could aggravate inflammation (Libby, 2012; Libby and Kobold, 2019). Inflammation mediated by microglia activation significantly promote neurodegeneration in the AD brain (Webers et al., 2020). Indomethacin, an anti-inflammatory agent, reduces systemic inflammation and deposition of AA amyloid in mice brain and attenuates the progression of Alzheimer's disease (Guo et al., 2002). Circulating inflammatory cytokines IL-1 $\beta$, IL-6, and CRP were elevated in T2 diabetes patients via nuclear factor- $\mathrm{B}(\mathrm{NF}-\kappa \mathrm{B})$ and JUN $\mathrm{N}$-terminal kinase (JNK) dependent pathways. IKK $\beta$ is a key downstream mediator of tissue inflammation. Using salicylates to inhibit IKK $\beta$ ameliorate glucose tolerance and decrease insulin resistance in the patients with type 2 diabetes (Hundal et al., 2002). Gut dysbiosis featured by changed gut microbiota composition and increased mucosal barrier permeability occurs with aging, it is reported to promote inflammaging and trigger cancers (Biragyn and Ferrucci, 2018). Interestingly, inflammasome can protect against carcinogenesis by activating innate immune reactions and triggering the pyroptosis of premalignant cells (Zitvogel et al., 2012, 2017). This suggest inflammaging might not simply play a vicious function, it is also a compensation mechanism to fight infections or tumorigenesis in response to immune function decline due to immunosenescence.

The mechanisms underneath inflammaging and its contribution to age-related diseases are poorly understood, yet in a great need to clarify. Inflammaging participates in several cellular and molecular mechanisms such as pro-inflammatory cytokine secretion, inflammasome activation, cellular senescence, dysregulation of the protein homeostasis, DNA damage response, etc (Ferrucci and Fabbri, 2018). Inflammaging is accompanied by increased pro-inflammatory or chemotactic factors such as TNF- $\alpha$, IL-1 $\beta$, IL-6, IL- 8 , IL-18, and C-C motif chemokine 2 (CCL2) (Vandanmagsar et al., 2011; Shakeri et al., 2018). These cytokines, most of which are SASP members, further activate several inflammatory signal pathways (Schmitz et al., 2011; Liu et al., 2017). For example, cigarette can activate pulmonary NF- $\mathrm{B}$ pathway, leading to symptoms of IPF in mice. SRT1720, an activator of SIRT1, can suppress NF$\kappa \mathrm{B}$ pathway to improve lung health (Rahman et al., 2012). Vitamin D3 also inhibits inflammation via JAK-STAT3 pathway, another important inflammatory pathway, and attenuates the development of neurological diseases (Yasukawa et al., 2012; Boontanrart et al., 2016). Inflammasomes are assembled under the stimulation of damage-associated molecular patterns (DAMP) and pathogen associated molecular patterns (PAMPs). Activation of inflammasomes elevated the IL-1 $\beta$ and IL-18 levels and induced pancreatic $\beta$-cell apoptosis (Strowig et al., 2012). The mechanisms of inflammaging are complex involving pathways both in immunity regulation and aging progression. A better understanding of these unknown pathways could help to develop methods to suppress inflammaging and improve physiological functions.

The interventions extending lifespan or improving healthspan in animal models usually can suppress inflammation. Calorie restriction, the most classic way to extend lifespan, can effectively attenuate pro-inflammatory cells and inflammatory factors (Ma et al., 2020). Clearance of $\mathrm{p} 16^{\mathrm{Ink} 4 \mathrm{a}}$-positive senescent cells in INK-ATTAC mice via injection of senolytic drug AP20187 alleviates inflammation, delays oncogenesis and extends lifespan (Baker et al., 2016). Increasing eosinophils, an anti-infection white blood cell, reduces inflammation in adipose tissue and partially improves muscle tissues in old mouse (Brigger et al., 2020). Aspirin, a widely used anti-inflammatory drug, reduces beta-galactosidase activity and increases telomerase activity in replicative senescence endothelial cells (Bode-Boger et al., 2005; Zelenay et al., 2015). Overexpression of SIRT7 in breast cancer cells prevents the metastasis into lung by inhibiting TGF- $\beta$ signal pathway (Tang et al., 2017). Therefore, modulating inflammation could be effective therapeutic targets on increasing longevity and preventing age-related diseases.

\section{The Effects of SASP Factors on Neurological Functions}

Neurodegeneration is a common aging-related pathology. Senescence has been widely found in most types of cells in aged brain including neurons, microglia, astrocytes and neural stem cells ( $\mathrm{Si}$ et al., 2021). In the frontal cortices of Alzheimer's disease patients, high levels of $\mathrm{p} 16^{\mathrm{Ink} 4 \mathrm{a}}, \gamma \mathrm{H} 2 \mathrm{AX}$, and MMP1 were found in astrocytes linking to reduced lactic acid and antioxidant (Bhat et al., 2012). Senescent neural stem cells disrupt the generation of neurons, while the senescent neurons can induce secondary senescence on other cellular types causing functional decline. In aged mice, microglia exhibit increased production of the proinflammatory cytokines IL- 6 , IL- $1 \beta$, and TNF- $\alpha$, which damages the brain and increases neurodegeneration (Frederiksen et al., 2019). In old rats, astrocytes, microglia, and neurons secret pro-inflammatory cytokines including TNF- $\alpha$ and IL- $1 \beta$ to induce progressive degeneration (Lana et al., 2016). Senescent endothelial cells could promote the rupture of the blood-brain barrier, which makes it easier for the peripheral immune cells to enter the brain (Maciel-Barón et al., 2018). Senescence in brain can be aggravated by pathological changes. Aggregation of tau protein induced cellular senescence in the brain. Tau transgenic mice exerted senescence-like phenotypes including DNA damage, mitochondrial dysfunction and SASP (Musi et al., 2018). Overall, senescence is one of the major causes for the postmitotic brain cells to lose proper functions. The SASP factors generated from cells within or outside of central nervous system disrupt tissue homeostasis, increase neuroinflammation, and eventually contribute to the initiation or the progression of neurodegenerative diseases (Figure 2).

\section{The Effects of SASP Factors on Respiratory Functions}

With age advancing, the senescent epithelial cells and fibroblasts accumulate in adult lungs (Chen et al., 2019). The aging phenotypes in lung include pulmonary inflammation, high susceptibility to infections, loss of lung elastic recoil and enlargement of the distal air space (MacNee, 2016). The main causes of senescence in lung are replicative senescence, radiation or chemotherapy, and cigarette smoking (Rashid et al., 2018). In aging process or chronic lung diseases, endothelial cells and 
particularly fibroblasts undergo senescence (Yanai et al., 2015; Qiu et al., 2019; Gea et al., 2020). During the pathogenesis of chronic lung diseases especially IPF or COPD, cellular senescence and SASP factors act as pivotal driving forces. The senescent epithelial cells in the lungs of COPD patient produce SASP factors IL-1 $\beta$, IL-6, IL-8, and TNF- $\alpha$ (Kumar et al., 2014), which is usually due to NF-kB pathway activation in a p38-dependent manner (Maciel-Baron et al., 2016). Many intrinsic or external stressors can trigger SASP secretion via NF- $\mathrm{kB}$ signaling such as DNA damage, oxidative stress, inflammation, lung injuries, etc. (Rovillain et al., 2011; Salminen et al., 2012; Dong et al., 2015). The SASP response is activated by $\mathrm{p} 21^{\mathrm{CIP} 1}$, followed by activation of $\mathrm{p} 38$ mitogen-activated protein kinase and Janusactivated kinases, eventually results in the activation of NF- $\mathrm{KB}$ and secretion of proinflammatory cytokines (Soto-Gamez and Demaria, 2017). These SASP cytokines alter microenvironment adversely resulting in elevated inflammation, lung fibrosis and onset of aging and diseases. The senescence phenotypes in the fibroblasts of pulmonary fibrosis are so typical that many senolytic drug candidates or strategies are tested on mouse model of IPF (Lehmann et al., 2017; Schafer et al., 2017; Cai et al., 2020), and a recent progress is a human clinical trial testing therapeutic effects of dasatinib and quercetin (DQ) in human IPF patients (Justice et al., 2019).

\section{The Effects of SASP Factors on Cardiovascular Functions}

The heart is one of the least regenerative organs in the body and highly susceptible to cardiovascular diseases. Studies have shown that aging leads to structural and functional changes in myocardial cells. In the old people ( $>70$ years old), more than $50 \%$ cardiac progenitor cells $\left(\mathrm{Sca}-1^{+} / \mathrm{c}-\right.$ $\mathrm{kit}^{+} / \mathrm{CD} 31^{-} / \mathrm{CD} 5^{-} /$Tryptase $^{-}$) showed higher senescent biomarkers including $\mathrm{p} 16^{\text {Ink4a }}$ induction, SA-b-gal positivity, and increased $\gamma \mathrm{H} 2 \mathrm{AX}$ level and SASP secretion (LewisMcDougall et al., 2019). Single-nucleus quantification and clustering analysis showed that in heart cardiomyocyte and endothelial cells are the major cell types (Wolfien et al., 2020). Senescent cardiomyocytes can secrete atypical SASP factors such as endothelin 3 (EDN3), transforming growth factor $\beta 2$ (TGFB2) and growth differentiation factor 15 (GDF15) to induce senescence in neighboring cells (Anderson et al., 2019; Li et al., 2020a). endothelial cells form the lining of blood vessels and serve as the interface between vessels and tissues (Daneman and Prat, 2015). Senescent endothelial cells show increased endothelin-1 (ET-1) release and reduced nitric oxide (NO) production, which elevate local inflammation, induce atherosclerosis and damage vascular integrity (Uryga and Bennett, 2016). Vascular smooth muscle cells (VSMCs) are the basic component of the medial layer of arteries responsible for contraction/dilation (Lacolley et al., 2012). Apart from classic senescence features, senescent VSMCs affected signaling pathways like NO/cGMP signaling, voltagedependent and $\mathrm{Ca}^{2+}$-activated ion channels and the interactions of VSMCs with ECM (Rubio-Ruiz et al., 2014). Senescent VSMCs downregulated collagen and upregulated multiple cytokines in an IL-1 $\alpha$-dependent manner, driving adjacent VSMCs and ECs into a proinflammatory state (Gardner et al., 2015). Senescent VSMCs have abnormal response to Angiotensin-II (Ang-II), which causes increased DNA methyltransferase expression, elevated blood pressure and collagen deposition, ultimately lead to cardiac fibrosis (Domenighetti et al., 2005; Bacanamwo et al., 2007). Together, senescent heart cells and SASP cytokines contribute to the pathological symptoms of aged heart including arterial stiffening, cardiomyocyte hypertrophy and elevated myocardial fibrosis (Lakatta, 2003; Lakatta and Levy, 2003).

\section{The Effects of SASP Factors on Liver and Metabolism}

The liver is essential for regulating protein biosynthesis, energy metabolism and detoxification (Hunt et al., 2019). With aging, the number of hepatocytes decreases along with increased polyploidy, accumulation of senescent cells and reduced mitochondrial oxidative capacity (Basso et al., 1998). The hepatocytes can be induced into senescent state and subsequently produce SASP factors. Senescence and SASP can significantly affect metabolism and secretion panel of liver cells. The metabolism of the fibroblasts under influence of SASP factors undergo dramatic changes from mitochondrial dysfunction, hydrogen peroxide production, to a transition toward aerobic glycolysis (Pazolli et al., 2012), which in turn lead to increased production of high-energy metabolites into the microenvironment, along with ROS (Fane and Weeraratna, 2020). In a liver fibrosis and cirrhosis model, p53-expressing senescent stellate cells release IFN- $\gamma$ and IL-6, promote macrophage activation toward tumor-inhibiting M1state, whereas P53 null cells secrete IL-3, IL-4, and IL-5 that hinder macrophage activation and trapped in tumor-promoting M2-state (Lujambio et al., 2013). As a secretion organ, liver can secret its own anti-aging protein factor named Glycosylphosphatidylinositol-specific phospholipase D1 (GPLD1). It is carried to brain by blood to improve brain cognition function and neuron growth in rodents, while senescence in hepatocytes could impair this function (Horowitz et al., 2020). In summary, liver constantly guard metabolism and endocrine factors for intertissue communication that are both susceptible to senescence and SASP proinflammatory factors. Interestingly, in contrast to the common scenario of avoiding senescence and SASP, some research attempt to induce senescence on hepatocellular carcinoma cells by small molecules. A recent study successfully used the inhibitor of DNA-replication kinase CDC7 to selectively induce senescence in liver cancer cells with TP53 gene mutation but showing no effect on normal cells (Wang et al., 2019). It suggests senescence is not only a "destroyer," but also could be a useful weapon against cancer.

\section{The Effects of SASP Factors on Muscle Functions}

Normally, aging phenotypes in muscle include weight loss, lower grip strength, slow gait speed and decreased exercise endurance. Cellular senescence drives muscle aging mainly by causing muscle stem cell dysfunction. In muscles of old mice satellite cells entering senescence state due to high 
expression of $\mathrm{p} 16^{\text {Ink4a }}$ lost their regeneration ability, which can be reversed by silencing p $^{\text {Ink4a }}$ (Sousa-Victor et al., 2014). Muscle fusion and regeneration require successful completion of cellular communications mediated by lipids, membrane proteins, exosomes and cytokines such as Insulinlike growth factor (IGF-1), TGF $\beta$ or myostatin (Demonbreun and McNally, 2017). However, the main components of SASP factors like IL- 6 and TNF- $\alpha$ counteract insulin signaling and erythropoietin cascades, leading to insulin resistance and sarcopenia, a typical muscle aging phenotype (Beyer et al., 2012). It is interesting to notice that transient expression of IL-6 could be favorable for muscle regeneration after injury or during in vivo reprogramming (Ocampo et al., 2016; Chiche et al., 2017), indicating a context-dependent effect of IL-6. The spread of SASP cytokines also change muscle into more inflammatory microenvironment, like it does to other tissues. This age-elevated inflammation can promote muscle fibrosis and lead to chronic myopathy. For example, Sarcopenia has a strong inflammatory pathology due to senescence in muscle (Dalle et al., 2017). In contrast, strong evidence proves that exercise can reduce inflammation and improve muscle functions (Churchward-Venne et al., 2012). Overall, senescence and SASP appear to be the major contributors to muscle aging which validates elimination of senescent cells would be the most effective strategy to rejuvenate muscle functions.

\section{The Effects of SASP Factors on Skin}

Skin, as the largest organ of the human body, is the first protective shield against the external environment. Aging skin in nature is characterized by a loss of epidermal and dermal thickness, accompanied by loss of elasticity, dryness, wrinkle formation, dyspigmentation, slower wound healing, decreased collagen, and susceptibility to cancer (Ma et al., 2001; Mazini et al., 2021). Ultraviolet (UV) irradiation, a great risk factor of skin aging, induce DNA damage, ROS production, protein oxidation and lipid peroxidation by promoting the expression of MMPs (Noonan et al., 2012). MMP-1 is the primary cause of wrinkle formation for breaking down collagen fibers type I and III (Dong et al., 2008). Keratinocytes (KCs) is the outermost layer of the skin. UV induces senescence in $\mathrm{KCs}$, resulting in increased SA- $\beta$-gal activity, decreased Lamin B1 expression and elevated secretion of TNF-a, IL-1a, IL1b, or IL-6 (Wang and Dreesen, 2018). Similarly, senescent melanocytes secrete IL-6 and IL-8, which accelerate skin aging via activation of the TLR4-mediated ERK pathway (Seo et al., 2018; Victorelli et al., 2019). Activation of P38 MAPK signaling also increases the expression of MMPs that break down collagen to promote skin aging (Mavrogonatou et al., 2018). Senescence usually inhibits non-cell-autonomous growth and considered to suppress tumorigenesis. However, new evidence found that cellular senescence could stimulate skin carcinogenesis by elevating p38MAPK and MAPK/ERK signaling (Alimirah et al., 2020). Whether this is a common feature of senescence or a special event in skin requires further investigation.

\section{PART 2: CIRCULATING FACTORS THAT INFLUENCE AGING MICROENVIRONMENT AND POSSIBLE THERAPEUTIC TARGETS}

Circulating factors are the most fundamental intercellular regulators of microenvironment for their easy access into all the tissues or organs, and for the same reason, they are the most appealing therapeutic targets for anti-aging intervention. The metabolites and proteome profile in human blood have shown profound changes with aging (Auro et al., 2014; Lehallier et al., 2019). Understanding how these changes influence the whole system and drive the process of aging is crucial to developing efficient drugs for anti-aging medications. In the following section, we discuss three types of circulating factors that have seen substantial recent research advance that have been made such as $\mathrm{NAD}^{+}$, circulating proteins and RNA molecules, as well as their mechanisms and therapeutic potential.

\section{$\mathrm{NAD}^{+}$Is a Major Regulator of Intercellular Communication and a Promising Therapeutic Target of Anti-aging}

Nicotinamide adenine dinucleotide $\left(\mathrm{NAD}^{+}\right)$, a coenzyme for redox reactions and cofactor for $\mathrm{NAD}^{+}$-dependent enzymes represented by sirtuin family, CD38 and poly (ADP-ribose) polymerases family, is well known for its involvement in energy metabolism, DNA repair, epigenetic regulation, immune response, and cell senescence (Covarrubias et al., 2021). There is an age-dependent decline of $\mathrm{NAD}^{+}$content in various human tissues, which is linked to many aging-related diseases including metabolic dysfunctions, cardiovascular dysfunctions, skeletal muscle diseases, neurodegenerative disorders, hearing loss, innate immune dysfunctions, dysrhythmia, retinal degeneration, etc. (Fang et al., 2016; Chini et al., 2017). To counteract the $\mathrm{NAD}^{+}$decline, a new anti-aging strategy to augment $\mathrm{NAD}^{+}$ level in the old mice by administrating its precursors NMN or NR have demonstrated wide impacts on improving biological functions from metabolic functions (Elhassan et al., 2019), cognitive conditions (Tarantini et al., 2019), cardiovascular fitness (Das et al., 2018; Kiss et al., 2019a), immune response (Minhas et al., 2019), locomotor activity (Das et al., 2018), to even lifespan (Zhang et al., 2016). The large scale of $\mathrm{NAD}^{+}$impacts is ascribed to its mobile feature which enables it and its derived molecules to circulate in the microenvironment. Increasing $\mathrm{NAD}^{+}$level has a profound influence in the microenvironment and intercellular communication. Here, we discuss $\mathrm{NAD}^{+}$'s impact effects into three major aspects: (1) senescence and SASP; (2) impact on major biological processes such as metabolism, immune response, nervous and immune system and muscle function; and (3) functions of extracellular $\mathrm{NAD}^{+}$.

\section{Interplay of $\mathrm{NAD}^{+}$and Senescence}

The general $\mathrm{NAD}^{+}$decline during aging accelerates cell senescence. Hyperactivate PARP1, a NAD ${ }^{+}$-consuming enzyme, leads to decreased $\mathrm{NAD}^{+}$content and induce neuronal loss and 
elevated cellular senescence in tissues (Fang et al., 2016). Reduced availability of $\mathrm{NAD}^{+}$promoted cellular senescence in aging retinal pigment epithelium (Jadeja et al., 2018). Consistently, repletion of $\mathrm{NAD}^{+}$or reduce the consume of $\mathrm{NAD}^{+}$can rejuvenate senescence cells. For example, increasing $\mathrm{NAD}^{+}$ by supplementing its precursors can dramatically rejuvenate senescent cells, including stem cells, immune cells, generative cells, etc. (Han et al., 2016; Zhang et al., 2016; Yoshino et al., 2018). In the other direction, senescence can aggravate $\mathrm{NAD}^{+}$decline which possibly cause more senescence, forming a vicious cycle. When exposed to X-rays or $\gamma$-IR, HUVECs and MEFs were induced into senescence and secreted high level of inflammatory SASP factors such as IL-6, IL-8, and MCP-1, causing strong increase in expression and enzymatic activity of $\mathrm{CD} 38$, an $\mathrm{NAD}^{+}$catabolizing enzyme in murine bone marrow-derived macrophages (BMDM). Hyperactive CD38 consumed large amount of $\mathrm{NAD}^{+}$which is believed to be one of major causes for $\mathrm{NAD}^{+}$decline with age (Chini et al., 2019). However, inhibiting CD38 reversed age-related $\mathrm{NAD}^{+}$decline and prevented cellular senescence in tissues (Tarragó et al., 2018). Currently, $\mathrm{NAD}^{+}$-consuming enzymes inhibitors and $\mathrm{NAD}^{+}$precursors supplementation named as "NAD ${ }^{+}$boosting" therapy are under extensive study for preventing cell senescence and tissue aging. Interestingly, it is recently found that the intracellular $\mathrm{NAD}^{+}$level in the senescent proliferative exhaustion (PEsen) fibroblasts was somehow relatively maintained (James et al., 2016), despite of the evidences indicating the expression of $\mathrm{NAD}^{+}$-consuming enzymes SIRTs, PARPs, CD38 and bonemarrow stromal cell antigen 1 (BST1, CD157) $\mathrm{NAD}^{+}$hydrolases are all dramatically up-regulated in senescent cells (YamamotoKatayama et al., 2002; Aksoy et al., 2006; Liu et al., 2009; Mouchiroud et al., 2013; Gerdts et al., 2015). This conflict suggests $\mathrm{NAD}^{+}$metabolism might act in an unconventional way in the senescent cells which require further investigation.

$\mathrm{NAD}^{+}$influences not only cellular senescence but also SASP. NAD ${ }^{+}$affects SASP secretion mainly via its metaboliccontrol function. High levels of $\mathrm{NAD}^{+}$enhances glycolysis and mitochondrial respiration, which activates p38MAP kinase and stimulates NF- $\mathrm{B}$ transcription to induce the expression of proinflammatory cytokines (Mendelsohn and Larrick, 2019; Nacarelli et al., 2019). These cytokines elevate inflammatory environment and accelerate cancer progression. In pancreatic cancer mouse model or pancreatic ductal adenocarcinoma (PDAC) mouse model these cytokines elevate inflammatory environment and accelerate cancer progression (Guerra et al., 2011; Nacarelli et al., 2019). NAMPT, a critical NAD ${ }^{+}$synthesis enzyme, is found up-regulated in many solid tumors supporting tumor cells for their high demand of $\mathrm{NAD}^{+}$, which makes it a prognosis index for tumor malignancy or progression (Navas and Carnero, 2021). Inhibiting NAMPT's by FK866 improved immune microenvironment and the curative effect of chemotherapy (Taniguchi and Karin, 2018; Nacarelli et al., 2019). These evidences remind us that although senescence is tumorsuppressive, effects of SASP factors seem to be tumorigenic. The anti-aging effects of $\mathrm{NAD}^{+}$supplement require a tumor-free microenvironment. In addition to health status of the subject, the timing and dosage of $\mathrm{NAD}^{+}$supplement need to be carefully monitored too. Human body is too complicated for $\mathrm{NAD}^{+}$'s effects to be simply positive or negative, and most of time it is somewhere in-between. Therefore, much more still need to be known about how to bring out the "goodness" of $\mathrm{NAD}^{+}$ safely in the future.

\section{$\mathrm{NAD}^{+}$Regulates Metabolism by Stabilizing Glucose Homeostasis}

$\mathrm{NAD}^{+}$can alternate microenvironment by regulating metabolism. For example, $\mathrm{NAD}^{+}$is critical for beta cell function and regulation of glucose homeostasis. In mouse model, defects in $\mathrm{NAD}^{+}$biosynthesis impaired glucose-stimulated insulin secretion in pancreatic islets and disrupted glucose homeostasis, while treatment with NMN could increase glucose-stimulated insulin secretion and improve glucose intolerance (Revollo et al., 2007). Supplement of NMN can also increase insulin concentration in plasma and ameliorate insulin sensitivities of diet- or age-induced diabetes in mice (Yoshino et al., 2011). In a freshly released study of testing NMN in human, Samuel Klein's team conducted double-blind clinical trial and found that NMN could improve insulin sensitivity, insulin signaling and muscle tissue remodeling in the prediabetic women with overweight or obesity (Yoshino et al., 2021). The reduced $\mathrm{NAD}^{+}$regeneration in mitochondria due to insufficient ATP production drives cell metabolism into aerobic glycolysis, which may change the entire cellular microenvironment (Luengo et al., 2021). The nature of being a widely demanded substrate enables $\mathrm{NAD}^{+}$to have a profound impact in metabolism since many energy-generating reactions require it. It partly explains why supplementation of $\mathrm{NAD}^{+}$could have wide range of anti-aging effects across tissues.

\section{$\mathrm{NAD}^{+}$Improves Survival of Immune Cells and Regulates Inflammation Signaling in the Immune System}

The immune response function declines to a great extent with age (Weinberger, 2017), whereas $\mathrm{NAD}^{+}$replenishment is reported to ameliorate immune responses (Singhal and Cheng, 2019). $\mathrm{NAD}^{+}$has a natural link to immunology because it serves as substrate of receptor protein CD38/CD157 that are located on cell surface and responsible for evoking immune response. Since it is extracellular $\mathrm{NAD}^{+}$that $\mathrm{CD} 38$ mainly utilizes, we will elaborate on it in the later discussion. Here we focus on the link between intracellular $\mathrm{NAD}^{+}$and immune functions. Macrophages play an important role in the resolution of inflammation by secreting various cytokines (Watanabe et al., 2019). Increasing de novo biosynthesis of $\mathrm{NAD}^{+}$in aged macrophages can restore oxidative metabolism, improve immune responses and remodel macrophage polarization by activating SIRT3 and increasing QPRT expression (Minhas et al., 2019). NAD ${ }^{+}$depletion induced by NAMPT inhibitors changes immune microenvironment by recruiting $\mathrm{CD}^{+}, \mathrm{CD}^{+}$, and $\mathrm{CD}^{+} \mathrm{T}$ cells, and decreasing M2-polarized immunosuppressive macrophages and leads to enhanced checkpoint immunotherapy in glioblastoma (Li et al., 2020b). In addition to macrophages, $\mathrm{NAD}^{+}$also regulate other immune cells. In 2016, a study found that longterm administration of NMN can also significantly improve immune system function by increasing lymphocytes number 
(Mills et al., 2016). Increasing $\mathrm{NAD}^{+}$level by supplementing NMN can prevent NF- $\mathrm{BB}$ activation and control the ongoing inflammatory state by stabilizing telomeres and positively affecting functions of immune cells such as $\mathrm{T}$ lymphocytes, $\mathrm{B}$ lymphocytes, granulocytes, monocytes, and NK cell population (Omran and Almaliki, 2020). Taken together, efficient $\mathrm{NAD}^{+}$is a crucial for proper immune function and supplementing $\mathrm{NAD}^{+}$ has potential to combat the immune dysfunction caused by aging.

\section{$\mathrm{NAD}^{+}$Boosters Have Neuroprotective Functions}

The decreased $\mathrm{NAD}^{+}$with age compromises nervous system function by causing mitochondrial dysfunction, oxidative damage accumulation, lysosome dysfunction, calcium dysregulation, impaired stress responses, enhanced inflammation, damaged neurogenesis and telomere shortening (Lautrup et al., 2019; Covarrubias et al., 2021). $\mathrm{NAD}^{+}$ augmentation by NMN can decrease inflammation, restore mitochondrial function and bioenergetics of nervous system by enhancing neuronal survival, increasing neurovascular coupling responses and cognitive function in aged animals (Lautrup et al., 2019; Poddar et al., 2019). Additional studies suggested that the underlying mechanism might also involve the reduced DNA damage due to increased PARP1 activity and activation of SIRT1-PGC-1a pathways, given that $\mathrm{NAD}^{+}$is a substrate for both PARP1 and SIRT1 (Tarantini et al., 2019). Besides using precursors, overexpressing or activating key enzymes of $\mathrm{NAD}^{+}$biosynthesis to increase $\mathrm{NAD}^{+}$was also proved to be neuroprotective. For example, in Drosophila, overexpressing NMNAT could protect against tau or spinocerebellar ataxia 1 (SCA1) induced neurodegeneration (Ali et al., 2012). P7C3, a novel NAMPT activator, can protect against mitochondrial dissolution, enhance hippocampal neurogenesis and ameliorate cognitive in mice, suggesting that it could be a potential therapeutic candidate for treating neurological diseases (Wang et al., 2016). The studies on boosting $\mathrm{NAD}^{+}$in nervous system are relatively more comprehensive than other systems and some remarkable progress has been made in recent years. However, apart from that NAM has been proved to cross blood-brain barrier (Spector and Johanson, 2007), there is no evidence yet demonstrating either NMN or NR can do the same. Therefore, further investigation is needed to dissect whether these improved neurological functions are a direct result of $\mathrm{NAD}^{+}$boosting in the brain or an indirect benefit of the systematic $\mathrm{NAD}^{+}$restoration.

\section{NAD ${ }^{+}$Preserves Muscle Functions by Improving Mitochondrial Biogenesis and Reducing Inflammation} Skeletal muscle, an important organ that performs supportive, sportive, metabolic and endocrine functions, has decreased $\mathrm{NAD}^{+}$content with age due to the down-regulated expression of nicotinamide phosphoribosyltransferase (NAMPT), the ratelimiting enzyme in $\mathrm{NAD}^{+}$biosynthesis (de Guia et al., 2019). Decreased $\mathrm{NAD}^{+}$content may result in loss of skeletal muscle mass and weakened muscle function, a typical muscle pathology named sarcopenia (Dodds et al., 2015), while supplement of $\mathrm{NAD}^{+}$can improve skeletal muscle functions in old mice. For example, specifically overexpressing NAMPT in the skeletal muscle of 24-month-old mice can prominently improve their exercise capacity by increasing glycolytic and TCA cycle flux to levels comparable to young mice (Frederick et al., 2016). Besides genetic approach, replenishing NMN, NR or nicotinamide (NAM), precursors of $\mathrm{NAD}^{+}$, can also improve the pathologies of sarcopenia. A 12-month NMN administration to C57BL/6N mice beginning at age of 5 months had effectively increased $\mathrm{NAD}^{+}$content in skeletal muscle, enhanced mitochondrial respiratory capacity, and delayed the aging process based on the global gene expression profiles (Mills et al., 2016). In the obese mice, NMN treatment can increase $\mathrm{NAD}^{+}$levels and mitochondrial copy number in skeletal muscle (Uddin et al., 2016). Exogenous NAM supplementation to 28-monthold rats for 5 weeks can improve the exercise ability and metabolic level by regulating the SIRT1-PGC- $1 \alpha$ signaling pathway (Pajk et al., 2017). NR supplementation, unlike NMN or NAM, did not increase skeletal muscle $\mathrm{NAD}^{+}$content or skeletal muscle functions but did downregulate the expression of genes involved in glycolysis, TCA cycle and mitochondria biogenesis, both in old mice and elderly human (Yang et al., 2020). Despite this, NR supplementation reduced macrophage infiltration, demonstrating potent anti-inflammatory effects in aged mice muscle (Elhassan et al., 2019). Although the rational for the difference between NR and NMN remains unclear, these studies demonstrate that $\mathrm{NAD}^{+}$precursors have therapeutic potentials for anti-inflammatory treatment or sarcopenia in old muscle.

\section{Extracellular $\mathrm{NAD}^{+}$: Carry Out Inter-Tissue Communications}

Although $\mathrm{NAD}^{+}$is widely utilized within cells, it actually hardly diffuses through cell membrane (van Roermund et al., 1995). This is in line with the highly variant concentrations of $\mathrm{NAD}^{+}$in different tissues. The current intervention strategy for $\mathrm{NAD}^{+}$is to supplement membrane-permissible $\mathrm{NAD}^{+}$intermediate $\mathrm{NMN}$ or NR to manipulate $\mathrm{NAD}^{+}$production in cell (Yoshino et al., 2018). Is $\mathrm{NAD}^{+}$capable to influence across tissues? The answer is "yes." A secreted form of $\mathrm{NAD}^{+}$synthesis enzyme eNAMPT (also named as PBEF or Visfatin), secreted by adipose tissue, can increase $\mathrm{NAD}^{+}$content in hypothalamus, hippocampus, pancreas, or retina and delay aging in mice (Yoon et al., 2015; Yoshida et al., 2019). However, it is also reported to have some malignant functions, for example, to induce endothelial dysfunction by activating NLRP3 inflammasome and facilitate release of IL-1 $\beta$ (Romacho et al., 2020) or to amplify preclinical acute lung injury (Quijada et al., 2020), or to cause mouse and human beta cell dysfunction in type 2 diabetes at high concentrations (Sayers et al., 2020). Given its flexible nature of being a cytokine, eNAMPT has a potential to impact across tissues and channel $\mathrm{NAD}^{+}$metabolism systematically in human body, which makes it a promising intervention target for the future research.

Extracellular $\mathrm{NAD}^{+}$itself can be signaling messengers. It was reported to elevate cytosol calcium signaling and promote apoptosis in the cultured human osteoblastic cells (Romanello et al., 2001). CD38 and CD157, existing on the outer membrane of cell, catalyze the cleavage of extracellular $\mathrm{NAD}^{+}$into ADP-ribose or cyclic ADP-ribose, which are responsible for 
activating immune function and induce antibody response (Partida-Sánchez et al., 2004). In addition, extracellular NAD ${ }^{+}$ induce apoptosis in mice $\mathrm{T}$ cells but not $\mathrm{B}$ cells, possibly due to the cleavage by another membrane protein mono-ADPribosyl transferases (ARTs) (Seman et al., 2003). In summary, although extracellular $\mathrm{NAD}^{+}$barely diffuse into cytosol, itself or derived molecules from its catabolism can transduce signals into cell to induce immune responses cascade. Since most of the extracellular $\mathrm{NAD}^{+}$molecules probably come from the broken cells as a result of stimulus or stress, this makes it a suitable "sensor" to initiate self-defense mechanisms such as immune clearance. The research on functions of extracellular $\mathrm{NAD}^{+}$has been long overlooked which deserves a deeper investigation in the future.

\section{Circulating Protein Factors in Blood and Their Anti-aging Effects}

The suspicion that blood carries anti-aging factors has a long history traced back to the rumors that vampires stay young by drinking human blood. A number of studies using parabiosis technique to channel blood streams of young and old mice had supported the prediction that certain factors related to aging circulate in the blood and manipulating their levels may have anti-aging effects (Finerty, 1952; Wright et al., 2001; Conboy et al., 2005). The parabiotic pairings between old and young mice enhanced the proliferation of skeletal muscle stem cells in the old mice by activating Notch signaling pathway and regenerating the aged hepatocytes by restoring cEBP- $\alpha$ complex (Conboy et al., 2005). Exposing old mice to the blood of the young parabiotic partner restored remyelination capacity in the central nervous system of old mice to produce new myelin sheaths by recruiting bloodderived monocytes from young mice (Ruckh et al., 2012). The old mice sharing blood stream with young mice for 4 weeks displayed dramatical improvement in their cardiovascular system including regressed cardiac hypertrophy, reduced cardiomyocyte size and remodeled molecular events. In this study, they used proteomics analysis to successfully identify the TGF $\beta$ superfamily member GDF11 is the circulating factor in young mice that improved the cardiac hypertrophy of old mice (Loffredo et al., 2013). However, another study later reported the contradict finding that GDF11 increased with age and repressed muscle regeneration (Egerman et al., 2015; Schafer et al., 2016). The anti-aging function of circulating GDF11 is still currently under debate.

Despite of the controversy about GDF11, researchers continue to search for factors critical for aging progress in the blood. A recent study found that prostaglandin-degrading enzyme 15PGDH elevated in aged mice and contributed to sarcopenia. Pharmaceutically inhibition of $15-\mathrm{PGDH}$ increased muscle mass and strength in old mice by increasing PGE2 levels, also improved mitochondrial function and autophagy by decreasing TGF-beta and ubiquitin- proteasome pathways (Palla et al., 2021). Another new finding reported that in aging macrophages and microglia, the lipid messenger prostaglandin E2 (PGE2), a major circulating modulator of inflammation, could reduce glucose flux and mitochondrial respiration through its EP2 receptor. The inhibition of myeloid EP2 sufficiently to restore cognition in aged mice by rejuvenating cellular bioenergetics, decreasing brain inflammation, and increasing hippocampal synaptic plasticity along with spatial memory (Minhas et al., 2021). The thrombospondin-4 (THBS4) and SPARC-like protein 1 (SPARCL1) that are enriched in young mice's serum could also rejuvenate brain functions by promoting synapse formation and NMDA receptor recruitment (Gan and Sudhof, 2019). These studies prove that certain proteins or messenger molecules in the blood indeed involve in regulating metabolisms in tissues, which reassure the necessity to keep on searching for circulating factors with antiaging effects.

\section{RNA Molecules and Their Roles in Shaping Aging Microenvironment}

Besides proteins, cell-free nucleic acid molecules are emerging candidates of the beneficial factors for aging that attract relatively less research attentions. A large number of secreted circulating non-coding RNAs (ncRNAs) were found to influence senescence and the outcomes of age-related diseases by modulating microenvironment. For example, LncRNA-ANRIL inhibited cellular senescence of VSMCs by up-regulating miR181a and down-regulating SIRT1 (Tan et al., 2019). LncRNANEAT1 promoted autophagy in the mice with MPTP-induced Parkinson's disease by stabilizing PINK1 protein and reducing miR-374c-5p (Yan et al., 2018; Dong et al., 2021). In addition, NEAT1 accelerated the progression of liver fibrosis and hepatocellular carcinoma (HCCs) (Bu et al., 2020). In rheumatoid arthritis, secretion of LncRNA-HOTAIR is elevated to promote dissolution of bone and cartilage matrix, and the level of LncRNA-HOTAIR in serum can be used as a novel non-invasive biomarker for the diagnosis of rheumatoid arthritis (Song et al., 2015). In osteoarthritis, mesenchymal stem cells (MSCs) secreted KLF3-AS1 to inhibit apoptosis and promote proliferation of chondrocytes, resulting in increased secretion of miR-372-3p that promotes apoptosis of MSCs (Liu et al., 2018). In muscle, miR-199-3p was reported to enhance myogenic differentiation and muscle regeneration. Its decline with aging results in muscle fiber atrophy and loss of muscle strength, which can be rescued by administering miR-199-3p mimics (Fukuoka et al., 2021). As matter of fact, unlike proteins, circulating RNA's effects on aging are, mostly tissue/organ specific and vary depending on the types of the source or recipient cells. One of such examples is LncRNA-MALAT1. Endothelial progenitor cells secreted LncRNA-MALAT1 to inactivate miR-124/ITGB1 pathway and promote migration of bone marrow-derived macrophage and differentiation of osteoclast precursors (Cui et al., 2019). But in atherosclerosis, LncRNA-MALAT1 secreted by HUVECs promotes M2 macrophage polarization via NF- $\kappa \mathrm{B} / \mathrm{TNF}-\alpha$ pathway (Huang et al., 2018). Interestingly, a recent research studied the miRNA profile of the NMN-treated old mice that had shown significant functional vascular rejuvenation. The authors found that dozens of miRNAs up-regulated by NMN 
might contribute to the anti-aging changes in vascular function through anti-atherogenic effects and epigenetic rejuvenation (Kiss et al., 2019b). This study established a link between miRNAs and other major aging regulating factors, implying possible interplay.

Circular RNAs (circRNAs) are a new type of non-coding RNA molecules that regulates age-related diseases. The circRNAs are generated by back-splicing, which connects the downstream 5' splice donor site with upstream 3' the recipient site on the mRNA transcript, forming covalently closed loop structure (Starke et al., 2015). These circRNAs are specifically expressed during aging course of nervous system, muscle, skin, and visual system (Cai et al., 2019). Various microarray or RNAseq studies suggested that fibrosis is often accompanied with the reduction or accumulation of different circRNAs ( $\mathrm{Li}$ et al., 2018), which contribute to the pathogenesis. For example, based on the study on 306 blood samples of elderly people from the InCHIANTI study, circDEF6, circEP300, circFOXO3 and circFNDC3B were demonstrated to be age-associated (Haque et al., 2020). CircFOXO3 could combine with proteins including anti-senescence protein ID-1, transcription factor E2F1, Focal Adhesion Kinase (FAK) and HIF1 $\alpha$, to promote cardiac senescence (Du et al., 2016a). CircFoxo3 could also sequester cyclin CDK2 and P21 to prevent CDK2 from binding cyclin E, blocking cell cycle progression in the G1 phase (Du et al., 2016b). Silencing circFoxo3 could alleviate doxorubicin-induced cardiomyopathy (Du et al., 2016a). These findings suggest RNAs may act as a new biological marker of aging and shed light on new potential targets for anti-aging therapy.

Exploring the circulating aging-related factors in blood or inbetween tissues has been a hot spot ever since modern aging research began. The attraction about this concept is that it is easier to be translated into anti-aging interventions and should have more systematically effects given the fact that blood basically can reach all the tissues. A number of therapeutic strategies interfering with circulating factors have proven anti-aging effects in brain, muscle or cardiovascular functions. So far these studies only looked into a certain type of tissue or organ. It is not clear whether rejuvenating multiple tissues could be achieved by a single circulating factor or multiple ones. It is a necessary question for scientists to solve in the future.

\section{CONCLUSION AND FUTURE DIRECTION}

In summary, we discussed the major mechanisms that could systematically change physiological functions at intercellular level and reshape microenvironment toward aging direction. Senescence and its secretion phenotype SASP are the most fundamental player here. They directly change compositions of cell population by arresting the proliferation of progenitor cells or release pro-inflammatory factors to chronically elevate basal inflammation level causing systematic inflammaging. The effects of senescence and SASP are "erosive." Once it starts, it has the potential to spread via the flowing cytokines to induce secondary senescence in the remote. Elimination of senescent cells by senolytic drugs has been proven to be effective to counteract senescence in natural aging or age-related disease model (Kirkland and Tchkonia, 2017; Ge et al., 2021). Recently, the first clinical trial of senolytic drug was conducted in human with IPF. Surprisingly, instead of rescuing lung functions, there was significant improvement in locomotors function such as walking distance or gait speed (Justice et al., 2019). Although it is a mystery why the drug failed to take effect in lungs where the most of senescent cells existing in IPF patients, it is still exciting to see the improvement in motor functions which proved senescence communicate at inter-tissue levels. In the future, increasing the specificities of senolytic drug might help to better cure aging-related diseases. In the meantime, techniques to monitor or trace the primary senescence onset spot could also be helpful to constrain senescence at earliest stage as possible to avoid further damages.

In contrast to senescence and SASP, $\mathrm{NAD}^{+}$and circulating anti-aging factors are mostly the mechanisms to counteract aging progression. The impacts of $\mathrm{NAD}^{+}$supplementation on intracellular biological functions have been extensively studied, while the systematic effects of $\mathrm{NAD}^{+}$at intercellular level still need a better understanding. When administrating $\mathrm{NAD}^{+}$ precursors $\mathrm{NMN}$ or $\mathrm{NR}, \mathrm{NAD}^{+}$concentrations do not increase at same levels in different tissues due to different accessibility or expression levels of $\mathrm{NAD}^{+}$synthesis enzymes, which inevitably lead to different responses. The discovery of eNAMPT enzyme indicates that there exist inter-tissue communications to control or compensate the discrepancy of $\mathrm{NAD}^{+}$production between tissues. Extracellular $\mathrm{NAD}^{+}$metabolism remains a mystery yet deserves more research attentions. There are solid evidence supporting young blood can rejuvenate the physiology functions of old mice, proving the existence of certain circulating factors in the young mice that could help the old. Future study should keep making efforts to investigate these possible candidates. Blood has complicated composition. The currently proved aging-related circulating factors are not only proteins but also microRNAs. It should be kept in open mind that any component in blood, for example metabolite or hormone, could be aging-related. It is also possible that not a single factor but a combination of them involved. Regardless, more efforts still need to be made in searching for anti-aging factors in blood.

\section{AUTHOR CONTRIBUTIONS}

QT and XZ were responsible for writing Part 1. NL and JL were responsible for writing Part 2. QT designed the figures with the images modified from Servier Medical Art (Servier, www.smart.servier.com, licensed under a Creative Commons Attribution 3.0 Unported Licence). All the authors contributed to the article and approved the submitted version.

\section{FUNDING}

This work was supported by grants from the State Key Laboratory Special Fund (2060204) and Chinese Academy of Medical Sciences Innovation Fund for Medical Sciences (2018-I2M-1-002). 


\section{REFERENCES}

Acosta, J. C., Banito, A., Wuestefeld, T., Georgilis, A., Janich, P., Morton, J. P., et al. (2013). A complex secretory program orchestrated by the inflammasome controls paracrine senescence. Nat. Cell Biol. 15, 978-990. doi: 10.1038/ ncb2784

Ahadi, S., Zhou, W., Schüssler-Fiorenza Rose, S., Sailani, M., Contrepois, K., Avina, M., et al. (2020). Personal aging markers and ageotypes revealed by deep longitudinal profiling. Nat. Med. 26, 83-90. doi: 10.1038/s41591-019-0719-5

Aksoy, P., White, T. A., Thompson, M., and Chini, E. N. (2006). Regulation of intracellular levels of NAD: a novel role for CD38. Biochem. Biophys. Res. Commun. 345, 1386-1392. doi: 10.1016/j.bbrc.2006.05.042

Ali, Y. O., Ruan, K., and Zhai, R. G. (2012). NMNAT suppresses tauinduced neurodegeneration by promoting clearance of hyperphosphorylated tau oligomers in a Drosophila model of tauopathy. Hum. Mol. Genet. 21, 237-250. doi: 10.1093/hmg/ddr449

Alimirah, F., Pulido, T., Valdovinos, A., Alptekin, S., Chang, E., Jones, E., et al. (2020). Cellular senescence promotes skin carcinogenesis through p38MAPK and p44/42MAPK signaling. Cancer Res. 80, 3606-3619. doi: 10.1158/00085472.CAN-20-0108

Alley, D. E., Crimmins, E., Bandeen-Roche, K., Guralnik, J., and Ferrucci, L. (2007). Three-year change in inflammatory markers in elderly people and mortality: the invecchiare in Chianti study. J. Am. Geriatr. Soc. 55, 1801-1807. doi: 10.1111/j. 1532-5415.2007.01390.x

Amor, C., Feucht, J., Leibold, J., Ho, Y. J., Zhu, C., Alonso-Curbelo, D., et al. (2020). Senolytic CAR T cells reverse senescence-associated pathologies. Nature 583, 127-132. doi: 10.1038/s41586-020-2403-9

Anderson, R., Lagnado, A., Maggiorani, D., Walaszczyk, A., Dookun, E., Chapman, J., et al. (2019). Length-independent telomere damage drives postmitotic cardiomyocyte senescence. EMBO J. 38:e100492. doi: 10.15252/embj. 2018100492

Arai, Y., Martin-Ruiz, C. M., Takayama, M., Abe, Y., Takebayashi, T., Koyasu, S., et al. (2015). Inflammation, but not telomere length, predicts successful ageing at extreme old age: a longitudinal study of semi-supercentenarians. EBio Med. 2, 1549-1558. doi: 10.1016/j.ebiom.2015.07.029

Armutcu, F. (2019). Organ crosstalk: the potent roles of inflammation and fibrotic changes in the course of organ interactions. Inflamm. Res. 68, 825-839. doi: 10.1007/s00011-019-01271-7

Auro, K., Joensuu, A., Fischer, K., Kettunen, J., Salo, P., Mattsson, H., et al. (2014). A metabolic view on menopause and ageing. Nat. Commun. 5:4708. doi: $10.1038 /$ ncomms5708

Aw, D., Silva, A., and Palmer, D. (2007a). Immunosenescence: emerging challenges for an ageing population. Immunology 120, 435-446. doi: 10.1111/j.1365-2567. 2007.02555.x

Aw, D., Silva, A. B., and Palmer, D. B. (2007b). Immunosenescence: emerging challenges for an ageing population. Immunology 120, 435-446.

Baar, M. P., Brandt, R. M. C., Putavet, D. A., Klein, J. D. D., Derks, K. W. J., Bourgeois, B. R. M., et al. (2017). Targeted apoptosis of senescent cells restores tissue homeostasis in response to chemotoxicity and Aging. Cell 169, 132147.e116. doi: 10.1016/j.cell.2017.02.031

Bacanamwo, M., Akinbami, M., Wang, D., and Gibbons, G. H. (2007). Inhibition of DNA methyltransferase inhibits the ang ii-induced increase in blood pressure, vascular remodeling and target organ damage. Circulation 116:II(124).

Baker, D. J., Childs, B. G., Durik, M., Wijers, M. E., Sieben, C. J., Zhong, J., et al. (2016). Naturally occurring p16(Ink4a)-positive cells shorten healthy lifespan. Nature 530, 184-189. doi: 10.1038/nature16932

Baker, D. J., Wijshake, T., Tchkonia, T., LeBrasseur, N. K., Childs, B. G., van de Sluis, B., et al. (2011). Clearance of p16Ink4a-positive senescent cells delays ageing-associated disorders. Nature 479, 232-236. doi: 10.1038/nature 10600

Basso, A., Piantanelli, L., Rossolini, G., and Roth, G. (1998). Reduced DNA synthesis in primary cultures of hepatocytes from old mice is restored by thymus grafts. J. Gerontol. A Biol. Sci. Med. Sci. 53, B111-B116. doi: 10.1093/ gerona/53a.2.b111

Beyer, I., Mets, T., and Bautmans, I. (2012). Chronic low-grade inflammation and age-related sarcopenia. Curr. Opin. Clin. Nutr. Metab. Care 15, 12-22. doi: 10.1097/MCO.0b013e32834dd297
Bhat, R., Crowe, E., Bitto, A., Moh, M., Katsetos, C., Garcia, F., et al. (2012). Astrocyte senescence as a component of Alzheimer's disease. PLoS One 7:e45069. doi: 10.1371/journal.pone.0045069

Biragyn, A., and Ferrucci, L. (2018). Gut dysbiosis: a potential link between increased cancer risk in ageing and inflammaging. Lancet Oncol. 19, e295-e304. doi: 10.1016/S1470-2045(18)30095-0

Bode-Boger, S. M., Martens-Lobenhoffer, J., Tager, M., Schroder, H., and Scalera, F. (2005). Aspirin reduces endothelial cell senescence. Biochem. Biophys. Res. Commun. 334, 1226-1232. doi: 10.1016/j.bbrc.2005.07.014

Boontanrart, M., Hall, S. D., Spanier, J. A., Hayes, C. E., and Olson, J. K. (2016). Vitamin D3 alters microglia immune activation by an IL-10 dependent SOCS3 mechanism. J. Neuroimmunol. 292, 126-136. doi: 10.1016/j.jneuroim.2016. 01.015

Braumuller, H., Wieder, T., Brenner, E., Assmann, S., Hahn, M., Alkhaled, M., et al. (2013). T-helper-1-cell cytokines drive cancer into senescence. Nature 494, 361-365. doi: 10.1038/nature11824

Brigger, D., Riether, C., van Brummelen, R., Mosher, K. I., Shiu, A., Ding, Z., et al. (2020). Eosinophils regulate adipose tissue inflammation and sustain physical and immunological fitness in old age. Nat. Metab. 2, 688-702. doi: 10.1038/ s42255-020-0228-3

Bu, F. T., Wang, A., Zhu, Y., You, H. M., Zhang, Y. F., Meng, X. M., et al. (2020). LncRNA NEAT1: shedding light on mechanisms and opportunities in liver diseases. Liver Int. 40, 2612-2626. doi: 10.1111/liv.14629

Cai, H., Li, Y., Niringiyumukiza, J. D., Su, P., and Xiang, W. (2019). Circular RNA involvement in aging: an emerging player with great potential. Mech. Ageing Dev. 178, 16-24. doi: 10.1016/j.mad.2018.11.002

Cai, Y., Zhou, H., Zhu, Y., Sun, Q., Ji, Y., Xue, A., et al. (2020). Elimination of senescent cells by beta-galactosidase-targeted prodrug attenuates inflammation and restores physical function in aged mice. Cell Res. 30, 574-589. doi: 10.1038/ s41422-020-0314-9

Campisi, J. (2013). Aging, cellular senescence, and cancer. Annu. Rev. Physiol. 75, 685-705. doi: 10.1146/annurev-physiol-030212-183653

Chen, X., Xu, H., Hou, J., Wang, H., Zheng, Y., Li, H., et al. (2019). Epithelial cell senescence induces pulmonary fibrosis through Nanog-mediated fibroblast activation. Aging 12, 242-259. doi: 10.18632/aging.102613

Chiche, A., Le Roux, I., von Joest, M., Sakai, H., Aguin, S. B., Cazin, C., et al. (2017). Injury-Induced Senescence Enables In Vivo Reprogramming in Skeletal Muscle. Cell Stem Cell 20, 407-414.e404. doi: 10.1016/j.stem.2016.11.020

Childs, B. G., Baker, D. J., Wijshake, T., Conover, C. A., Campisi, J., and van Deursen, J. M. (2016). Senescent intimal foam cells are deleterious at all stages of atherosclerosis. Science 354, 472-477. doi: 10.1126/science.aaf6659

Childs, B. G., Durik, M., Baker, D. J., and van Deursen, J. M. (2015). Cellular senescence in aging and age-related disease: from mechanisms to therapy. Nat. Med. 21, 1424-1435. doi: 10.1038/nm.4000

Chilosi, M., Carloni, A., Rossi, A., and Poletti, V. (2013). Premature lung aging and cellular senescence in the pathogenesis of idiopathic pulmonary fibrosis and COPD/emphysema. Transl. Res. 162, 156-173. doi: 10.1016/j.trsl.2013.06.004

Chini, C., Hogan, K. A., Warner, G. M., Tarragó, M. G., Peclat, T. R., Tchkonia, T., et al. (2019). The NADase CD38 is induced by factors secreted from senescent cells providing a potential link between senescence and age-related cellular $\mathrm{NAD}(+)$ decline. Biochem. Biophys. Res. Commun. 513, 486-493. doi: 10.1016/ j.bbrc.2019.03.199

Chini, C. C. S., Tarragó, M. G., and Chini, E. N. (2017). NAD and the aging process: role in life, death and everything in between. Mol. Cell Endocrinol. 455, 62-74. doi: 10.1016/j.mce.2016.11.003

Churchward-Venne, T. A., Burd, N. A., and Phillips, S. M. (2012). Nutritional regulation of muscle protein synthesis with resistance exercise: strategies to enhance anabolism. Nutr. Metab. 9:40. doi: 10.1186/1743-7075-9-40

Conboy, I. M., Conboy, M. J., Wagers, A. J., Girma, E. R., Weissman, I. L., and Rando, T. A. (2005). Rejuvenation of aged progenitor cells by exposure to a young systemic environment. Nature 433, 760-764. doi: 10.1038/nature 03260

Coppe, J. P., Desprez, P. Y., Krtolica, A., and Campisi, J. (2010). The senescenceassociated secretory phenotype: the dark side of tumor suppression. Annu. Rev Pathol. 5, 99-118. doi: 10.1146/annurev-pathol-121808-102144

Covarrubias, A. J., Perrone, R., Grozio, A., and Verdin, E. (2021). NAD(+) metabolism and its roles in cellular processes during ageing. Nat. Rev. Mol. Cell Biol. 22, 119-141. doi: 10.1038/s41580-020-00313-x 
Cui, Y., Fu, S., Sun, D., Xing, J., Hou, T., and Wu, X. (2019). EPC-derived exosomes promote osteoclastogenesis through LncRNA-MALAT1. J. Cell Mol. Med. 23, 3843-3854. doi: $10.1111 /$ jcmm. 14228

Dalle, S., Rossmeislova, L., and Koppo, K. (2017). The role of inflammation in age-related sarcopenia. Front. Physiol. 8:1045. doi: 10.3389/fphys.2017.01045

Daneman, R., and Prat, A. (2015). The blood-brain barrier. Cold Spring Harb. Perspect. Biol. 7:a020412. doi: 10.1101/cshperspect.a020412

Das, A., Huang, G. X., Bonkowski, M. S., Longchamp, A., Li, C., Schultz, M. B., et al. (2018). Impairment of an endothelial NAD(+)-H2S signaling network is a reversible cause of vascular Aging. Cell 173, 74-89.e20. doi: 10.1016/j.cell.2018. 02.008

de Guia, R. M., Agerholm, M., Nielsen, T. S., Consitt, L. A., Søgaard, D., Helge, J. W., et al. (2019). Aerobic and resistance exercise training reverses agedependent decline in $\mathrm{NAD}(+)$ salvage capacity in human skeletal muscle. Physiol. Rep. 7:e14139. doi: 10.14814/phy2.14139

Demaria, M., Ohtani, N., Youssef, S. A., Rodier, F., Toussaint, W., Mitchell, J. R., et al. (2014). An essential role for senescent cells in optimal wound healing through secretion of PDGF-AA. Dev. Cell 31, 722-733. doi: 10.1016/j.devcel. 2014.11.012

Demonbreun, A., and McNally, E. (2017). Muscle cell communication in development and repair. Curr. Opin. Pharmacol. 34, 7-14. doi: 10.1016/j.coph. 2017.03.008

Dodds, R. M., Roberts, H. C., Cooper, C., and Sayer, A. A. (2015). The epidemiology of sarcopenia. J. Clin. Densitom. 18, 461-466. doi: 10.1016/j.jocd.2015.04.012

Domenighetti, A. A., Wang, Q., Egger, M., Richards, S. M., Pedrazzini, T., and Delbridge, L. M. (2005). Angiotensin II-mediated phenotypic cardiomyocyte remodeling leads to age-dependent cardiac dysfunction and failure. Hypertension 46, 426-432. doi: 10.1161/01.HYP.0000173069.53 699.d9

Dong, K. K., Damaghi, N., Picart, S. D., Markova, N. G., Obayashi, K., Okano, Y., et al. (2008). UV-induced DNA damage initiates release of MMP-1 in human skin. Exp. Dermatol. 17, 1037-1044. doi: 10.1111/j.1600-0625.2008.00 747.x

Dong, L., Zheng, Y., Gao, L., and Luo, X. (2021). lncRNA NEAT1 prompts autophagy and apoptosis in MPTP-induced Parkinson's disease by impairing miR-374c-5p. Acta Biochim. Biophys. Sin. 53, 870-882. doi: 10.1093/abbs/ gmab055

Dong, X., Tong, F., Qian, C., Zhang, R., Dong, J., Wu, G., et al. (2015). NEMO modulates radiation-induced endothelial senescence of human umbilical veins through NF-kappaB signal pathway. Radiat. Res. 183, 82-93. doi: 10.1667/ RR13682.1

Du, W. W., Yang, W., Chen, Y., Wu, Z.-K., Foster, F. S., Yang, Z., et al. (2016a). Foxo3 circular RNA promotes cardiac senescence by modulating multiple factors associated with stress and senescence responses. Eur. Heart J. 38, 1402-1412. doi: 10.1093/eurheartj/ehw001

Du, W. W., Yang, W., Liu, E., Yang, Z., Dhaliwal, P., and Yang, B. B. (2016b). Foxo3 circular RNA retards cell cycle progression via forming ternary complexes with p21 and CDK2. Nucleic Acids Res. 44, 2846-2858. doi: 10.1093/nar/ gkw027

Egerman, M. A., Cadena, S. M., Gilbert, J. A., Meyer, A., Nelson, H. N., Swalley, S. E., et al. (2015). GDF11 increases with age and inhibits skeletal muscle regeneration. Cell Metab. 22, 164-174. doi: 10.1016/j.cmet.2015. 05.010

Elhassan, Y. S., Kluckova, K., Fletcher, R. S., Schmidt, M. S., Garten, A., Doig, C. L., et al. (2019). Nicotinamide riboside augments the aged human skeletal muscle $\mathrm{NAD}(+)$ metabolome and induces transcriptomic and antiinflammatory signatures. Cell Rep. 28, 1717-1728.e1716. doi: 10.1016/j.celrep. 2019.07.043

Fafian-Labora, J. A., and O'Loghlen, A. (2020). Classical and nonclassical intercellular communication in senescence and Ageing. Trends Cell Biol. 30, 628-639. doi: 10.1016/j.tcb.2020.05.003

Fane, M., and Weeraratna, A. T. (2020). How the ageing microenvironment influences tumour progression. Nat. Rev. Cancer 20, 89-106. doi: 10.1038/ s41568-019-0222-9

Fang, E. F., Kassahun, H., Croteau, D. L., Scheibye-Knudsen, M., Marosi, K., Lu, H., et al. (2016). $\mathrm{NAD}(+)$ replenishment improves lifespan and healthspan in ataxia telangiectasia models via mitophagy and DNA repair. Cell Metab. 24, 566-581. doi: 10.1016/j.cmet.2016.09.004
Ferrucci, L., and Fabbri, E. (2018). Inflammageing: chronic inflammation in ageing, cardiovascular disease, and frailty. Nat. Rev. Cardiol. 15, 505-522. doi: 10.1038/ s41569-018-0064-2

Finerty, J. C. (1952). Parabiosis in physiological studies. Physiol. Rev. 32, 277-302. doi: 10.1152/physrev.1952.32.3.277

Franceschi, C., and Campisi, J. (2014). Chronic inflammation (inflammaging) and its potential contribution to age-associated diseases. J. Gerontol. A Biol. Sci. Med. Sci. 69(Suppl.1), S4-S9. doi: 10.1093/gerona/glu057

Franceschi, C., Garagnani, P., Parini, P., Giuliani, C., and Santoro, A. (2018). Inflammaging: a new immune-metabolic viewpoint for age-related diseases. Nat. Rev. Endocrinol. 14, 576-590. doi: 10.1038/s41574-018-0059-4

Frasca, D., Blomberg, B. B., and Paganelli, R. (2017). Aging, obesity, and inflammatory age-related diseases. Front. Immunol. 8:1745. doi: 10.3389/ fimmu.2017.01745

Frederick, D. W., Loro, E., Liu, L., Davila, A. Jr., Chellappa, K., Silverman, I. M., et al. (2016). Loss of NAD homeostasis leads to progressive and reversible degeneration of skeletal muscle. Cell Metab. 24, 269-282. doi: 10.1016/j.cmet. 2016.07.005

Frederiksen, H. R., Haukedal, H., and Freude, K. (2019). Cell type specific expression of toll-like receptors in human brains and implications in Alzheimer's disease. Biomed. Res. Int. 2019:7420189. doi: 10.1155/2019/ 7420189

Freund, A., Laberge, R. M., Demaria, M., and Campisi, J. (2012). Lamin B1 loss is a senescence-associated biomarker. Mol. Biol. Cell 23, 2066-2075. doi: 10.1091/ mbc.E11-10-0884

Freund, A., Orjalo, A. V., Desprez, P. Y., and Campisi, J. (2010). Inflammatory networks during cellular senescence: causes and consequences. Trends Mol. Med. 16, 238-246. doi: 10.1016/j.molmed.2010.03.003

Fukuoka, M., Fujita, H., Numao, K., Nakamura, Y., Shimizu, H., Sekiguchi, M., et al. (2021). MiR-199-3p enhances muscle regeneration and ameliorates aged muscle and muscular dystrophy. Commun. Biol. 4:427. doi: 10.1038/s42003021-01952-2

Fulop, T., Larbi, A., and Witkowski, J. M. (2019). Human Inflammaging. Gerontology 65, 495-504. doi: 10.1159/000497375

Gan, K. J., and Sudhof, T. C. (2019). Specific factors in blood from young but not old mice directly promote synapse formation and NMDA-receptor recruitment. Proc Natl. Acad. Sci. U.S.A. 116, 12524-12533. doi: 10.1073/pnas.190267 2116

Gardner, S., Humphry, M., Bennett, M., and Clarke, M. (2015). Senescent vascular smooth muscle cells drive inflammation through an interleukin-1 $\alpha$-dependent senescence-associated secretory phenotype. Arterioscler. Thromb. Vasc. Biol. 35, 1963-1974. doi: 10.1161/atvbaha.115.305896

Ge, M., Hu, L., Ao, H., Zi, M., Kong, Q., and He, Y. (2021). Senolytic targets and new strategies for clearing senescent cells. Mech. Ageing Dev. 195:111468. doi: 10.1016/j.mad.2021.111468

Gea, J., Ausin, P., Martinez-Llorens, J. M., and Barreiro, E. (2020). Respiratory muscle senescence in ageing and chronic lung diseases. Eur. Respir. Rev. 29:200087. doi: 10.1183/16000617.0087-2020

Gerdts, J., Brace, E. J., Sasaki, Y., DiAntonio, A., and Milbrandt, J. (2015). SARM1 activation triggers axon degeneration locally via $\mathrm{NAD}^{+}$destruction. Science 348, 453-457. doi: 10.1126/science. 1258366

Gorgoulis, V., Adams, P., Alimonti, A., Bennett, D., Bischof, O., Bishop, C., et al. (2019). Cellular senescence: defining a path forward. Cell 179, 813-827. doi: 10.1016/j.cell.2019.10.005

Guerra, C., Collado, M., Navas, C., Schuhmacher, A. J., Hernández-Porras, I., Cañamero, M., et al. (2011). Pancreatitis-induced inflammation contributes to pancreatic cancer by inhibiting oncogene-induced senescence. Cancer Cell 19, 728-739. doi: 10.1016/j.ccr.2011.05.011

Guo, J. T., Yu, J., Grass, D., de Beer, F. C., and Kindy, M. S. (2002). Inflammationdependent cerebral deposition of serum amyloid a protein in a mouse model of amyloidosis. J. Neurosci. 22, 5900-5909. doi: 10.1523/JNEUROSCI.22-1405900.2002

Han, S. Y., Cho, M. J., Won, S., Hong, J. P., Bae, J. N., Cho, S. J., et al. (2015). Sociodemographic Factors and Comorbidities Associated with Remission from Alcohol Dependence: Results from a Nationwide General Population Survey in Korea. Psychiatry Invest. 12, 316-323. doi: 10.4306/pi.2015.12.3.316

Han, X., Tai, H., Wang, X., Wang, Z., Zhou, J., Wei, X., et al. (2016). AMPK activation protects cells from oxidative stress-induced senescence via 
autophagic flux restoration and intracellular NAD(+) elevation. Aging Cell 15, 416-427. doi: 10.1111/acel.12446

Haque, S., Ames, R. M., Moore, K., Pilling, L. C., Peters, L. L., Bandinelli, S., et al. (2020). circRNAs expressed in human peripheral blood are associated with human aging phenotypes, cellular senescence and mouse lifespan. Geroscience 42, 183-199. doi: 10.1007/s11357-019-00120-z

Hayflick, L., and Moorhead, P. S. (1961). The serial cultivation of human diploid cell strains. Exp. Cell Res. 25, 585-621. doi: 10.1016/0014-4827(61)90192-6

He, S., and Sharpless, N. E. (2017). Senescence in health and disease. Cell 169, 1000-1011. doi: 10.1016/j.cell.2017.05.015

Horowitz, A. M., Fan, X., Bieri, G., Smith, L. K., Sanchez-Diaz, C. I., Schroer, A. B., et al. (2020). Blood factors transfer beneficial effects of exercise on neurogenesis and cognition to the aged brain. Science 369, 167-173. doi: 10.1126/science. aaw 2622

Huang, C., Han, J., Wu, Y., Li, S., Wang, Q., Lin, W., et al. (2018). Exosomal MALAT1 derived from oxidized low-density lipoprotein-treated endothelial cells promotes M2 macrophage polarization. Mol. Med. Rep. 18, 509-515. doi: $10.3892 / \mathrm{mmr} .2018 .8982$

Hundal, R. S., Petersen, K. F., Mayerson, A. B., Randhawa, P. S., Inzucchi, S., Shoelson, S. E., et al. (2002). Mechanism by which high-dose aspirin improves glucose metabolism in type 2 diabetes. J. Clin. Invest. 109, 1321-1326. doi: 10.1172/JCI14955

Hunt, N., Kang, S., Lockwood, G., Le Couteur, D., and Cogger, V. (2019). Hallmarks of Aging in the liver. Comput. Struct. Biotechnol. J. 17, 1151-1161. doi: 10.1016/ j.csbj.2019.07.021

Ito, Y., Hoare, M., and Narita, M. (2017). Spatial and temporal control of senescence. Trends Cell Biol. 27, 820-832. doi: 10.1016/j.tcb.2017.07.004

Jadeja, R. N., Powell, F. L., Jones, M. A., Fuller, J., Joseph, E., Thounaojam, M. C., et al. (2018). Loss of NAMPT in aging retinal pigment epithelium reduces NAD (+) availability and promotes cellular senescence. Aging 10, 1306-1323. doi: 10.18632/aging.101469

James, E. L., Lane, J. A., Michalek, R. D., Karoly, E. D., and Parkinson, E. K. (2016). Replicatively senescent human fibroblasts reveal a distinct intracellular metabolic profile with alterations in NAD+ and nicotinamide metabolism. Sci. Rep. 6:38489. doi: 10.1038/srep38489

Jeon, O. H., David, N., Campisi, J., and Elisseeff, J. H. (2018). Senescent cells and osteoarthritis: a painful connection. J. Clin. Invest. 128, 1229-1237. doi: $10.1172 /$ jci95147

Jian, B., Hu, M., Cai, W., Zhang, B., and Lu, Z. (2020). Update of immunosenescence in cerebral small vessel disease. Front. Immunol. 11:585655. doi: $10.3389 /$ fimmu. 2020.585655

Jurk, D., Wilson, C., Passos, J. F., Oakley, F., Correia-Melo, C., Greaves, L., et al. (2014). Chronic inflammation induces telomere dysfunction and accelerates ageing in mice. Nat. Commun. 2:4172. doi: 10.1038/ncomms 5172

Justice, J. N., Nambiar, A. M., Tchkonia, T., LeBrasseur, N. K., Pascual, R., Hashmi, S. K., et al. (2019). Senolytics in idiopathic pulmonary fibrosis: Results from a first-in-human, open-label, pilot study. EBioMed. 40, 554-563. doi: 10.1016/j. ebiom.2018.12.052

Kirkland, J. L., and Tchkonia, T. (2017). Cellular senescence: a translational perspective. EBioMed. 21, 21-28. doi: 10.1016/j.ebiom.2017.04.013

Kiss, T., Balasubramanian, P., Valcarcel-Ares, M. N., Tarantini, S., Yabluchanskiy, A., Csipo, T., et al. (2019a). Nicotinamide mononucleotide (NMN) treatment attenuates oxidative stress and rescues angiogenic capacity in aged cerebromicrovascular endothelial cells: a potential mechanism for the prevention of vascular cognitive impairment. Geroscience 41, 619-630. doi: 10.1007/s11357-019-00074-2

Kiss, T., Giles, C. B., Tarantini, S., Yabluchanskiy, A., Balasubramanian, P., Gautam, T., et al. (2019b). Nicotinamide mononucleotide (NMN) supplementation promotes anti-aging miRNA expression profile in the aorta of aged mice, predicting epigenetic rejuvenation and anti-atherogenic effects. Geroscience 41, 419-439. doi: 10.1007/s11357-019-00095-x

Kumar, A., Bano, D., and Ehninger, D. (2020). Cellular senescence in vivo: from cells to tissues to pathologies. Mech. Ageing Dev. 190:111308. doi: 10.1016/j. mad.2020.111308

Kumar, M., Seeger, W., and Voswinckel, R. (2014). Senescence-associated secretory phenotype and its possible role in chronic obstructive pulmonary disease. Am. J. Respir. Cell Mol. Biol. 51, 323-333. doi: 10.1165/rcmb.2013-0382PS
Lacolley, P., Regnault, V., Nicoletti, A., Li, Z., and Michel, J.-B. (2012). The vascular smooth muscle cell in arterial pathology: a cell that can take on multiple roles. Cardiovasc. Res. 95, 194-204. doi: 10.1093/cvr/cvs135

Lakatta, E. (2003). Arterial and cardiac aging: major shareholders in cardiovascular disease enterprises: Part III: cellular and molecular clues to heart and arterial aging. Circulation 107, 490-497. doi: 10.1161/01.cir.0000048894.99 865.02

Lakatta, E., and Levy, D. (2003). Arterial and cardiac aging: major shareholders in cardiovascular disease enterprises: Part II: the aging heart in health: links to heart disease. Circulation 107, 346-354. doi: 10.1161/01.cir.0000048893.62 841.f7

Lana, D., Iovino, L., Nosi, D., Wenk, G. L., and Giovannini, M. G. (2016), The neuron-astrocyte-microglia triad involvement in neuroinflammaging mechanisms in the CA3 hippocampus of memory-impaired aged rats. Exp. Gerontol. 83, 71-88. doi: 10.1016/j.exger.2016.07.011

Lau, L., Porciuncula, A., Yu, A., Iwakura, Y., and David, G. (2019). Uncoupling the senescence-associated secretory phenotype from cell cycle exit via Interleukin 1 inactivation unveils its protumorigenic role. Mol. Cell Biol. 39:e00586-18. doi: 10.1128/MCB.00586-18

Lautrup, S., Sinclair, D. A., Mattson, M. P., and Fang, E. F. (2019). NAD(+) in brain aging and neurodegenerative disorders. Cell Metab. 30, 630-655. doi: 10.1016/j.cmet.2019.09.001

Lehallier, B., Gate, D., Schaum, N., Nanasi, T., Lee, S. E., Yousef, H., et al. (2019). Undulating changes in human plasma proteome profiles across the lifespan. Nat. Med. 25, 1843-1850. doi: 10.1038/s41591-019-0673-2

Lehmann, M., Korfei, M., Mutze, K., Klee, S., Skronska-Wasek, W., Alsafadi, H. N., et al. (2017). Senolytic drugs target alveolar epithelial cell function and attenuate experimental lung fibrosis ex vivo. Eur. Respir. J. 50:1602367. doi: 10.1183/13993003.02367-2016

Lewis-McDougall, F., Ruchaya, P., Domenjo-Vila, E., Shin Teoh, T., Prata, L., Cottle, B., et al. (2019). Aged-senescent cells contribute to impaired heart regeneration. Aging cell 18:e12931. doi: 10.1111/acel.12931

Li, H., Hastings, M., Rhee, J., Trager, L., Roh, J., and Rosenzweig, A. (2020a). Targeting age-related pathways in heart failure. Circ. Res. 126, 533-551. doi: 10.1161/circresaha.119.315889

Li, M., Kirtane, A. R., Kiyokawa, J., Nagashima, H., Lopes, A., Tirmizi, Z. A., et al. (2020b). Local targeting of $\mathrm{NAD}(+)$ salvage pathway alters the immune tumor microenvironment and enhances checkpoint immunotherapy in glioblastoma. Cancer Res. 80, 5024-5034. doi: 10.1158/0008-5472.can-20-1094

Li, R., Wang, Y., Song, X., Sun, W., Zhang, J., Liu, Y., et al. (2018). Potential regulatory role of circular RNA in idiopathic pulmonary fibrosis. Int. J. Mol. Med. 42, 3256-3268. doi: 10.3892/ijmm.2018.3892

Libby, P. (2012). Inflammation in atherosclerosis. Arterioscler. Thromb. Vasc. Biol. 32, 2045-2051. doi: 10.1161/ATVBAHA.108.179705

Libby, P., and Kobold, S. (2019). Inflammation: a common contributor to cancer, aging, and cardiovascular diseases-expanding the concept of cardio-oncology. Cardiovasc. Res. 115, 824-829. doi: 10.1093/cvr/cvz058

Liu, D., Gharavi, R., Pitta, M., Gleichmann, M., and Mattson, M. P. (2009). Nicotinamide prevents NAD+ depletion and protects neurons against excitotoxicity and cerebral ischemia: NAD+ consumption by SIRT1 may endanger energetically compromised neurons. Neuromol. Med. 11, 28-42. doi: 10.1007/s12017-009-8058-1

Liu, T., Zhang, L., Joo, D., and Sun, S. C. (2017). NF-kappaB signaling in inflammation. Signal. Transduct. Target Ther. 2:17023. doi: 10.1038/sigtrans. 2017.23

Liu, Y., Lin, L., Zou, R., Wen, C., Wang, Z., and Lin, F. (2018). MSC-derived exosomes promote proliferation and inhibit apoptosis of chondrocytes via lncRNA-KLF3-AS1/miR-206/GIT1 axis in osteoarthritis. Cell Cycle 17, 24112422. doi: $10.1080 / 15384101.2018 .1526603$

Loffredo, F. S., Steinhauser, M. L., Jay, S. M., Gannon, J., Pancoast, J. R., Yalamanchi, P., et al. (2013). Growth differentiation factor 11 is a circulating factor that reverses age-related cardiac hypertrophy. Cell 153, 828-839. doi: 10.1016/j.cell. 2013.04.015

Lopez-Otin, C., Blasco, M. A., Partridge, L., Serrano, M., and Kroemer, G. (2013). The hallmarks of aging. Cell 153, 1194-1217. doi: 10.1016/j.cell.2013.05.039

Luengo, A., Li, Z., Gui, D. Y., Sullivan, L. B., Zagorulya, M., Do, B. T., et al. (2021). Increased demand for $\mathrm{NAD}(+)$ relative to ATP drives aerobic glycolysis. Mol Cell 81, 691-707.e696. doi: 10.1016/j.molcel.2020.12.012 
Lujambio, A., Akkari, L., Simon, J., Grace, D., Tschaharganeh, D., Bolden, J., et al. (2013). Non-cell-autonomous tumor suppression by p53. Cell 153, 449-460. doi: 10.1016/j.cell.2013.03.020

Ma, S., Sun, S., Geng, L., Song, M., Wang, W., Ye, Y., et al. (2020). Caloric restriction reprograms the single-cell transcriptional landscape of rattus norvegicus Aging. Cell 180, 984-1001.e1022. doi: 10.1016/j.cell.2020. 02.008

Ma, W., Wlaschek, M., Tantcheva-Poor, I., Schneider, L. A., Naderi, L., Razi-Wolf, Z., et al. (2001). Chronological ageing and photoageing of the fibroblasts and the dermal connective tissue. Clin. Exp. Dermatol. 26, 592-599. doi: 10.1046/j. 1365-2230.2001.00905.x

Maciel-Barón, L., Moreno-Blas, D., Morales-Rosales, S., González-Puertos, V., López-Díazguerrero, N., Torres, C., et al. (2018). Cellular senescence, neurological function, and redox state. Antiox. Redox Signal. 28, 1704-1723. doi: 10.1089/ars.2017.7112

Maciel-Baron, L. A., Morales-Rosales, S. L., Aquino-Cruz, A. A., Triana-Martinez, F., Galvan-Arzate, S., Luna-Lopez, A., et al. (2016). Senescence associated secretory phenotype profile from primary lung mice fibroblasts depends on the senescence induction stimuli. Age 38:26. doi: 10.1007/s11357-016-9886-1

MacNee, W. (2016). Is chronic obstructive pulmonary disease an accelerated aging disease? Ann. Am. Thorac. Soc. 13(Suppl.5), S429-S437. doi: 10.1513/ AnnalsATS.201602-124AW

Mavrogonatou, E., Konstantinou, A., and Kletsas, D. (2018). Long-term exposure to TNF-alpha leads human skin fibroblasts to a p38 MAPK- and ROS-mediated premature senescence. Biogerontology 19, 237-249. doi: 10.1007/s10522-0189753-9

Mazini, L., Rochette, L., Hamdan, Y., and Malka, G. (2021). Skin immunomodulation during regeneration: emerging new targets. J. Pers. Med. 11:85. doi: 10.3390/jpm11020085

Mendelsohn, A. R., and Larrick, J. W. (2019). Interacting $\mathrm{NAD}(+)$ and cell senescence pathways complicate antiaging therapies. Rejuvenation Res. 22, 261-266. doi: 10.1089/rej.2019.2218

Miller, A. H., and Raison, C. L. (2016). The role of inflammation in depression: from evolutionary imperative to modern treatment target. Nat. Rev. Immunol. 16, 22-34. doi: 10.1038/nri.2015.5

Mills, K. F., Yoshida, S., Stein, L. R., Grozio, A., Kubota, S., Sasaki, Y., et al. (2016). Long-term administration of nicotinamide mononucleotide mitigates age-associated physiological decline in mice. Cell Metab. 24, 795-806. doi: 10.1016/j.cmet.2016.09.013

Minhas, P. S., Latif-Hernandez, A., McReynolds, M. R., Durairaj, A. S., Wang, Q., Rubin, A., et al. (2021). Restoring metabolism of myeloid cells reverses cognitive decline in ageing. Nature 590, 122-128. doi: 10.1038/s41586-020-03160-0

Minhas, P. S., Liu, L., Moon, P. K., Joshi, A. U., Dove, C., Mhatre, S., et al. (2019). Macrophage de novo $\mathrm{NAD}(+)$ synthesis specifies immune function in aging and inflammation. Nat. Immunol. 20, 50-63. doi: 10.1038/s41590-018-0255-3

Mouchiroud, L., Houtkooper, R. H., Moullan, N., Katsyuba, E., Ryu, D., Cantó, C., et al. (2013). The $\mathrm{NAD}(+) /$ sirtuin pathway modulates longevity through activation of mitochondrial UPR and FOXO signaling. Cell 154, 430-441. doi: 10.1016/j.cell.2013.06.016

Musi, N., Valentine, J., Sickora, K., Baeuerle, E., Thompson, C., Shen, Q., et al. (2018). Tau protein aggregation is associated with cellular senescence in the brain. Aging cell 17:e12840. doi: 10.1111/acel.12840

Nacarelli, T., Lau, L., Fukumoto, T., Zundell, J., Fatkhutdinov, N., Wu, S., et al. (2019). NAD metabolism governs the proinflammatory senescence-associated secretome. Nat. Cell Biol. 21, 397-407. doi: 10.1038/s41556-019-0287-4

Navas, L. E., and Carnero, A. (2021). NAD(+) metabolism, stemness, the immune response, and cancer. Signal. Transduct. Target Ther. 6:2. doi: 10.1038/s41392020-00354-w

Nehme, J., Borghesan, M., Mackedenski, S., Bird, T., and Demaria, M. (2020). Cellular senescence as a potential mediator of COVID-19 severity in the elderly. Aging cell 19:e13237. doi: 10.1111/acel.13237

Noonan, F. P., Zaidi, M. R., Wolnicka-Glubisz, A., Anver, M. R., Bahn, J., Wielgus, A., et al. (2012). Melanoma induction by ultraviolet A but not ultraviolet B radiation requires melanin pigment. Nat. Commun. 3:884. doi: 10.1038/ ncomms 1893

Ocampo, A., Reddy, P., Martinez-Redondo, P., Platero-Luengo, A., Hatanaka, F., Hishida, T., et al. (2016). In vivo amelioration of age-associated hallmarks by partial reprogramming. Cell 167, 1719-1733.e1712. doi: 10.1016/j.cell.2016 11.052

Ogrodnik, M., Evans, S. A., Fielder, E., Victorelli, S., Kruger, P., Salmonowicz, H., et al. (2021). Whole-body senescent cell clearance alleviates age-related brain inflammation and cognitive impairment in mice. Aging Cell 20:e13296. doi: 10.1111/acel.13296

Omran, H. M., and Almaliki, M. S. (2020). Influence of NAD+ as an ageingrelated immunomodulator on COVID 19 infection: A hypothesis. J. Infect. Public Health 13, 1196-1201. doi: 10.1016/j.jiph.2020.06.004

Pajk, M., Cselko, A., Varga, C., Posa, A., Tokodi, M., Boldogh, I., et al. (2017). Exogenous nicotinamide supplementation and moderate physical exercise can attenuate the aging process in skeletal muscle of rats. Biogerontology 18, 593600. doi: 10.1007/s10522-017-9705-9

Palla, A. R., Ravichandran, M., Wang, Y. X., Alexandrova, L., Yang, A. V., Kraft, P., et al. (2021). Inhibition of prostaglandin-degrading enzyme 15-PGDH rejuvenates aged muscle mass and strength. Science 371:eabc8059. doi: 10.1126/ science.abc8059

Partida-Sánchez, S., Goodrich, S., Kusser, K., Oppenheimer, N., Randall, T. D., and Lund, F. E. (2004). Regulation of dendritic cell trafficking by the ADP-ribosyl cyclase CD38: impact on the development of humoral immunity. Immunity 20, 279-291. doi: 10.1016/s1074-7613(04)00048-2

Pazolli, E., Alspach, E., Milczarek, A., Prior, J., Piwnica-Worms, D., and Stewart, S. A. (2012). Chromatin remodeling underlies the senescence-associated secretory phenotype of tumor stromal fibroblasts that supports cancer progression. Cancer Res. 72, 2251-2261. doi: 10.1158/0008-5472.CAN-113386

Poddar, S. K., Sifat, A. E., Haque, S., Nahid, N. A., Chowdhury, S., and Mehedi, I. (2019). Nicotinamide mononucleotide: exploration of diverse therapeutic applications of a potential molecule. Biomolecules 9:34.

Qiu, T., Tian, Y., Gao, Y., Ma, M., Li, H., Liu, X., et al. (2019). PTEN loss regulates alveolar epithelial cell senescence in pulmonary fibrosis depending on Akt activation. Aging 11, 7492-7509. doi: 10.18632/aging.102262

Quijada, H., Bermudez, T., Kempf, C. L., Valera, D. G., Garcia, A. N., Camp, S. M., et al. (2020). Endothelial eNAMPT amplifies preclinical acute lung injury: efficacy of an eNAMPT-neutralising mAb. Eur. Respir. J. 57:2002536. doi: 10.1183/13993003.02536-2020

Rahman, I., Kinnula, V. L., Gorbunova, V., and Yao, H. (2012). SIRT1 as a therapeutic target in inflammaging of the pulmonary disease. Prev. Med. 54(Suppl), S20-S28.

Rampelli, S., Candela, M., Turroni, S., Biagi, E., Collino, S., Franceschi, C., et al. (2013). Functional metagenomic profiling of intestinal microbiome in extreme ageing. Aging 5, 902-912. doi: 10.18632/aging.100623

Rashid, K., Sundar, I., Gerloff, J., Li, D., and Rahman, I. (2018). Lung cellular senescence is independent of aging in a mouse model of COPD/emphysema. Sci. Rep. 8:9023. doi: 10.1038/s41598-018-27209-3

Revollo, J. R., Körner, A., Mills, K. F., Satoh, A., Wang, T., Garten, A., et al. (2007). Nampt/PBEF/Visfatin regulates insulin secretion in beta cells as a systemic NAD biosynthetic enzyme. Cell Metab. 6, 363-375. doi: 10.1016/j.cmet.2007. 09.003

Ritschka, B., Storer, M., Mas, A., Heinzmann, F., Ortells, M. C., Morton, J. P., et al. (2017). The senescence-associated secretory phenotype induces cellular plasticity and tissue regeneration. Genes Dev. 31, 172-183. doi: 10.1101/gad. 290635.116

Romacho, T., Valencia, I., Ramos-González, M., Vallejo, S., López-Esteban, M., Lorenzo, O., et al. (2020). Visfatin/eNampt induces endothelial dysfunction in vivo: a role for toll-like receptor 4 and NLRP3 inflammasome. Sci. Rep. 10:5386. doi: 10.1038/s41598-020-62190-w

Romanello, M., Padoan, M., Franco, L., Veronesi, V., Moro, L., and D’Andrea, P. (2001). Extracellular $\mathrm{NAD}(+)$ induces calcium signaling and apoptosis in human osteoblastic cells. Biochem. Biophys. Res. Commun. 285, 1226-1231. doi: 10.1006/bbrc.2001.5325

Rovillain, E., Mansfield, L., Caetano, C., Alvarez-Fernandez, M., Caballero, O. L., Medema, R. H., et al. (2011). Activation of nuclear factor-kappa B signalling promotes cellular senescence. Oncogene 30, 2356-2366. doi: 10.1038/onc. 2010.611

Rubio-Ruiz, M., Pérez-Torres, I., Soto, M., Pastelín, G., and Guarner-Lans, V. (2014). Aging in blood vessels. Medicinal agents FOR systemic arterial 
hypertension in the elderly. Ageing Res. Rev. 18, 132-147. doi: 10.1016/j.arr. 2014.10.001

Ruckh, J. M., Zhao, J. W., Shadrach, J. L., van Wijngaarden, P., Rao, T. N., Wagers, A. J., et al. (2012). Rejuvenation of regeneration in the aging central nervous system. Cell Stem Cell 10, 96-103. doi: 10.1016/j.stem.2011.11.019

Salminen, A., Kauppinen, A., and Kaarniranta, K. (2012). Emerging role of NFkappaB signaling in the induction of senescence-associated secretory phenotype (SASP). Cell Signal. 24, 835-845. doi: 10.1016/j.cellsig.2011.12.006

Sanada, F., Taniyama, Y., Muratsu, J., Otsu, R., Shimizu, H., Rakugi, H., et al. (2018). IGF binding protein-5 induces cell senescence. Front. Endocrinol. 9:53. doi: $10.3389 /$ fendo. 2018.00053

Sayers, S. R., Beavil, R. L., Fine, N. H. F., Huang, G. C., Choudhary, P., Pacholarz, K. J., et al. (2020). Structure-functional changes in eNAMPT at high concentrations mediate mouse and human beta cell dysfunction in type 2 diabetes. Diabetologia 63, 313-323. doi: 10.1007/s00125-019-05029-y

Schafer, M. J., Atkinson, E. J., Vanderboom, P. M., Kotajarvi, B., White, T. A., Moore, M. M., et al. (2016). Quantification of GDF11 and myostatin in human aging and cardiovascular disea cell metab se. Cell Metab. 23, 1207-1215. doi: 10.1016/j.cmet.2016.05.023

Schafer, M. J., White, T. A., Iijima, K., Haak, A. J., Ligresti, G., Atkinson, E. J., et al. (2017). Cellular senescence mediates fibrotic pulmonary disease. Nat. Commun. 8:14532. doi: $10.1038 /$ ncomms 14532

Schmitz, M. L., Weber, A., Roxlau, T., Gaestel, M., and Kracht, M. (2011). Signal integration, crosstalk mechanisms and networks in the function of inflammatory cytokines. Biochim. Biophys. Acta 1813, 2165-2175. doi: 10.1016/ j.bbamcr.2011.06.019

Seman, M., Adriouch, S., Scheuplein, F., Krebs, C., Freese, D., Glowacki, G., et al. (2003). NAD-induced T cell death: ADP-ribosylation of cell surface proteins by ART2 activates the cytolytic P2X7 purinoceptor. Immunity 19, 571-582. doi: 10.1016/s1074-7613(03)00266-8

Seo, S., Park, S., Oh, S., and Shin, O. (2018). TLR4-mediated activation of the ERK pathway following UVA irradiation contributes to increased cytokine and MMP expression in senescent human dermal fibroblasts. PLoS One 13:e0202323. doi: 10.1371/journal.pone.0202323

Shakeri, H., Lemmens, K., Gevaert, A. B., De Meyer, G. R. Y., and Segers, V. F. M. (2018). Cellular senescence links aging and diabetes in cardiovascular disease. Am. J. Physiol. Heart Circ. Physiol. 315, H448-H462. doi: 10.1152/ajpheart. 00287.2018

Si, Z., Sun, L., and Wang, X. (2021). Evidence and perspectives of cell senescence in neurodegenerative diseases. Biomed. Pharmacother. 137:111327. doi: 10.1016/j. biopha.2021.111327

Singhal, A., and Cheng, C. Y. (2019). Host NAD+ metabolism and infections: therapeutic implications. Int. Immunol. 31, 59-67. doi: 10.1093/intimm/dxy068

Smith, A. J., and Humphries, S. E. (2009). Cytokine and cytokine receptor gene polymorphisms and their functionality. Cytok. Growth Factor Rev. 20, 43-59. doi: 10.1016/j.cytogfr.2008.11.006

Song, J., Kim, D., Han, J., Kim, Y., Lee, M., and Jin, E. J. (2015). PBMC and exosome-derived Hotair is a critical regulator and potent marker for rheumatoid arthritis. Clin. Exp. Med. 15, 121-126. doi: 10.1007/s10238-0130271-4

Soto-Gamez, A., and Demaria, M. (2017). Therapeutic interventions for aging: the case of cellular senescence. Drug Discov. Today 22, 786-795. doi: 10.1016/j. drudis.2017.01.004

Sousa-Victor, P., Gutarra, S., Garcia-Prat, L., Rodriguez-Ubreva, J., Ortet, L., RuizBonilla, V., et al. (2014). Geriatric muscle stem cells switch reversible quiescence into senescence. Nature 506, 316-321. doi: 10.1038/nature13013

Spector, R., and Johanson, C. E. (2007). Vitamin transport and homeostasis in mammalian brain: focus on Vitamins B and E. J. Neurochem. 103, 425-438. doi: 10.1111/j.1471-4159.2007.04773.x

Starke, S., Jost, I., Rossbach, O., Schneider, T., Schreiner, S., Hung, L. H., et al. (2015). Exon circularization requires canonical splice signals. Cell Rep. 10, 103-111. doi: 10.1016/j.celrep.2014.12.002

Strowig, T., Henao-Mejia, J., Elinav, E., and Flavell, R. (2012). Inflammasomes in health and disease. Nature 481, 278-286. doi: 10.1038/nature10759

Tan, P., Guo, Y., Zhan, J., Long, L., Xu, M., Ye, L., et al. (2019). LncRNAANRIL inhibits cell senescence of vascular smooth muscle cells by regulating miR-181a/Sirt1. Biochem. Cell Biol. 97, 571-580. doi: 10.1139/bcb-20180126
Tang, X., Shi, L., Xie, N., Liu, Z., Qian, M., Meng, F., et al. (2017). SIRT7 antagonizes TGF-beta signaling and inhibits breast cancer metastasis. Nat. Commun. 8:318. doi: 10.1038/s41467-017-00396-9

Taniguchi, K., and Karin, M. (2018). NF-кB, inflammation, immunity and cancer: coming of age. Nat. Rev. Immunol. 18, 309-324. doi: 10.1038/nri.2017.142

Tarantini, S., Valcarcel-Ares, M. N., Toth, P., Yabluchanskiy, A., Tucsek, Z., Kiss, T., et al. (2019). Nicotinamide mononucleotide (NMN) supplementation rescues cerebromicrovascular endothelial function and neurovascular coupling responses and improves cognitive function in aged mice. Redox Biol. 24:101192. doi: 10.1016/j.redox.2019.101192

Tarragó, M. G., Chini, C. C. S., Kanamori, K. S., Warner, G. M., Caride, A., de Oliveira, G. C., et al. (2018). A potent and specific CD38 inhibitor ameliorates age-related metabolic dysfunction by reversing tissue $\mathrm{NAD}(+)$ decline. Cell Metab. 27, 1081-1095.e1010. doi: 10.1016/j.cmet.2018.03.016

Tchkonia, T., Zhu, Y., van Deursen, J., Campisi, J., and Kirkland, J. L. (2013). Cellular senescence and the senescent secretory phenotype: therapeutic opportunities. J. Clin. Invest. 123, 966-972. doi: 10.1172/jci6 4098

Terlecki-Zaniewicz, L., Lämmermann, I., Latreille, J., Bobbili, M., Pils, V., Schosserer, M., et al. (2018). Small extracellular vesicles and their miRNA cargo are anti-apoptotic members of the senescence-associated secretory phenotype. Aging 10, 1103-1132. doi: 10.18632/aging.101452

Uddin, G. M., Youngson, N. A., Sinclair, D. A., and Morris, M. J. (2016). Head to head comparison of short-term treatment with the $\mathrm{NAD}(+)$ Precursor Nicotinamide Mononucleotide (NMN) and 6 weeks of exercise in obese female mice. Front. Pharmacol. 7:258. doi: 10.3389/fphar.2016.00258

Uryga, A. K., and Bennett, M. R. (2016). Ageing induced vascular smooth muscle cell senescence in atherosclerosis. J. Physiol. 594, 2115-2124. doi: 10.1113/ JP270923

Valentijn, F. A., Falke, L. L., Nguyen, T. Q., and Goldschmeding, R. (2018). Cellular senescence in the aging and diseased kidney. J. Cell Commun. Signal. 12, 69-82. doi: $10.1007 / \mathrm{s} 12079-017-0434-2$

van Deursen, J. M. (2014). The role of senescent cells in ageing. Nature 509, 439-446. doi: 10.1038/nature13193

van Roermund, C. W., Elgersma, Y., Singh, N., Wanders, R. J., and Tabak, H. F. (1995). The membrane of peroxisomes in Saccharomyces cerevisiae is impermeable to $\mathrm{NAD}(\mathrm{H})$ and acetyl-CoA under in vivo conditions. Embo J. 14, 3480-3486.

Vandanmagsar, B., Youm, Y. H., Ravussin, A., Galgani, J. E., Stadler, K., Mynatt, R. L., et al. (2011). The NLRP3 inflammasome instigates obesity-induced inflammation and insulin resistance. Nat. Med. 17, 179-188. doi: 10.1038/nm. 2279

Vasto, S., Carruba, G., Lio, D., Colonna-Romano, G., Di Bona, D., Candore, G., et al. (2009). Inflammation, ageing and cancer. Mech. Ageing Dev. 130, 40-45. doi: 10.1016/j.mad.2008.06.003

Victorelli, S., Lagnado, A., Halim, J., Moore, W., Talbot, D., Barrett, K., et al. (2019). Senescent human melanocytes drive skin ageing via paracrine telomere dysfunction. EMBO Front. Genet. J. 38:e101982. doi: 10.15252/embj. 2019101982

Wang, A. S., and Dreesen, O. (2018). Biomarkers of cellular senescence and skin Aging. Front. Genet. 9:247. doi: 10.3389/fgene.2018.00247

Wang, C., Vegna, S., Jin, H., Benedict, B., Lieftink, C., Ramirez, C., et al. (2019). Inducing and exploiting vulnerabilities for the treatment of liver cancer. Nature 574, 268-272. doi: 10.1038/s41586-019-1607-3

Wang, S. N., Xu, T. Y., Wang, X., Guan, Y. F., Zhang, S. L., Wang, P., et al. (2016). Neuroprotective efficacy of an aminopropyl carbazole derivative P7C3-A20 in ischemic stroke. CNS Neurosci. Ther. 22, 782-788. doi: 10.1111/cns.12576

Watanabe, S., Alexander, M., Misharin, A. V., and Budinger, G. R. S. (2019). The role of macrophages in the resolution of inflammation. J. Clin. Invest. 129, 2619-2628. doi: 10.1172/jci124615

Webers, A., Heneka, M. T., and Gleeson, P. A. (2020). The role of innate immune responses and neuroinflammation in amyloid accumulation and progression of Alzheimer's disease. Immunol. Cell. Biol. 98, 28-41. doi: 10.1111/imcb.12301

Weinberger, B. (2017). Immunosenescence: the importance of considering age in health and disease. Clin. Exp. Immunol. 187, 1-3. doi: 10.1111/cei.12879

Wiley, C. D., Velarde, M. C., Lecot, P., Liu, S., Sarnoski, E. A., Freund, A., et al. (2016). Mitochondrial dysfunction induces senescence with a distinct secretory phenotype. Cell Metab. 23, 303-314. doi: 10.1016/j.cmet.2015.11.011 
Wilkinson, H. N., and Hardman, M. J. (2020). Senescence in wound repair: emerging strategies to target chronic healing wounds. Front. Cell Dev. Biol. 8:773. doi: $10.3389 /$ fcell.2020.00773

Wolfien, M., Galow, A., Müller, P., Bartsch, M., Brunner, R., Goldammer, T., et al. (2020). Single-nucleus sequencing of an entire mammalian heart: cell type composition and velocity. Cells 9:318. doi: 10.3390/cells9020318

Wright, D. E., Wagers, A. J., Gulati, A. P., Johnson, F. L., and Weissman, I. L. (2001). Physiological migration of hematopoietic stem and progenitor cells. Science 294, 1933-1936. doi: 10.1126/science.1064081

Yamamoto-Katayama, S., Ariyoshi, M., Ishihara, K., Hirano, T., Jingami, H., and Morikawa, K. (2002). Crystallographic studies on human BST-1/CD157 with ADP-ribosyl cyclase and NAD glycohydrolase activities. J. Mol. Biol. 316, 711-723. doi: 10.1006/jmbi.2001.5386

Yan, W., Chen, Z. Y., Chen, J. Q., and Chen, H. M. (2018). LncRNA NEAT1 promotes autophagy in MPTP-induced Parkinson's disease through stabilizing PINK1 protein. Biochem. Biophys. Res. Commun. 496, 1019-1024. doi: 10.1016/ j.bbrc.2017.12.149

Yanai, H., Shteinberg, A., Porat, Z., Budovsky, A., Braiman, A., Ziesche, R., et al. (2015). Cellular senescence-like features of lung fibroblasts derived from idiopathic pulmonary fibrosis patients. Aging 7, 664-672. doi: 10.18632/aging. 100807

Yang, Q., Cong, L., Wang, Y., Luo, X., Li, H., Wang, H., et al. (2020). Increasing ovarian $\mathrm{NAD}(+)$ levels improve mitochondrial functions and reverse ovarian aging. Free Radic. Biol. Med. 156, 1-10. doi: 10.1016/j.freeradbiomed.2020.05.003

Yasukawa, H., Nagata, T., Oba, T., and Imaizumi, T. (2012). SOCS3: A novel therapeutic target for cardioprotection. JAKSTAT 1, 234-240. doi: 10.4161/jkst. 22435

Yoon, M. J., Yoshida, M., Johnson, S., Takikawa, A., Usui, I., Tobe, K., et al. (2015). SIRT1-mediated eNAMPT secretion from adipose tissue regulates hypothalamic NAD+ and function in mice. Cell Metab. 21, 706-717. doi: 10. 1016/j.cmet.2015.04.002

Yoshida, M., Satoh, A., Lin, J. B., Mills, K. F., Sasaki, Y., Rensing, N., et al. (2019). Extracellular vesicle-contained eNAMPT delays aging and extends lifespan in mice. Cell Metab. 30, 329-342e.325. doi: 10.1016/j.cmet.2019.05.015
Yoshino, J., Baur, J. A., and Imai, S. I. (2018). NAD(+) intermediates: the biology and therapeutic potential of NMN and NR. Cell Metab. 27, 513-528. doi: 10. 1016/j.cmet.2017.11.002

Yoshino, J., Mills, K. F., Yoon, M. J., and Imai, S. (2011). Nicotinamide mononucleotide, a key $\mathrm{NAD}(+)$ intermediate, treats the pathophysiology of diet- and age-induced diabetes in mice. Cell Metab. 14, 528-536. doi: 10.1016/j. cmet.2011.08.014

Yoshino, M., Yoshino, J., Kayser, B. D., Patti, G., Franczyk, M. P., Mills, K. F., et al. (2021). Nicotinamide mononucleotide increases muscle insulin sensitivity in prediabetic women. Science 372, 1224-1229. doi: 10.1126/science.abe 9985

Zelenay, S., van der Veen, A. G., Bottcher, J. P., Snelgrove, K. J., Rogers, N., Acton, S. E., et al. (2015). Cyclooxygenase-dependent tumor growth through evasion of immunity. Cell 162, 1257-1270. doi: 10.1016/j.cell.2015. 08.015

Zhang, H., Ryu, D., Wu, Y., Gariani, K., Wang, X., Luan, P., et al. (2016). $\mathrm{NAD}(+)$ repletion improves mitochondrial and stem cell function and enhances life span in mice. Science 352, 1436-1443. doi: 10.1126/science.aaf 2693

Zitvogel, L., Kepp, O., Galluzzi, L., and Kroemer, G. (2012). Inflammasomes in carcinogenesis and anticancer immune responses. Nat. Immunol. 13, 343-351. doi: 10.1038/ni.2224

Zitvogel, L., Pietrocola, F., and Kroemer, G. (2017). Nutrition, inflammation and cancer. Nat. Immunol. 18, 843-850. doi: 10.1038/ni.3754

Conflict of Interest: The authors declare that the research was conducted in the absence of any commercial or financial relationships that could be construed as a potential conflict of interest.

Copyright $(2021$ Tan, Liang, Zhang and Li. This is an open-access article distributed under the terms of the Creative Commons Attribution License (CC BY). The use, distribution or reproduction in other forums is permitted, provided the original author(s) and the copyright owner(s) are credited and that the original publication in this journal is cited, in accordance with accepted academic practice. No use, distribution or reproduction is permitted which does not comply with these terms. 